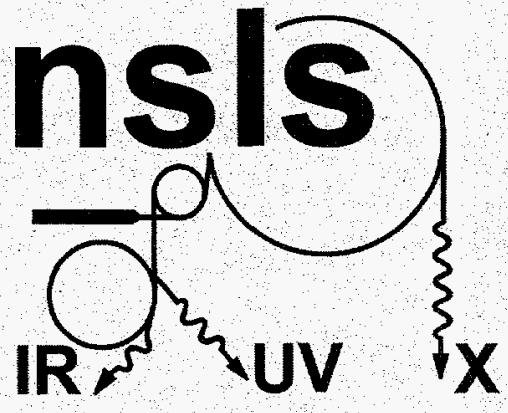

INFORMAL REPORT

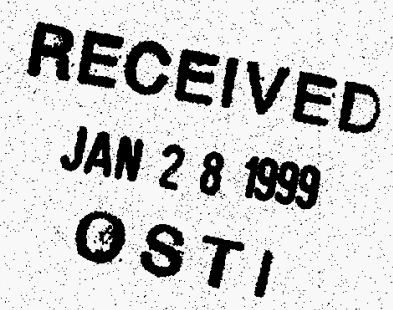

National Synchrotron Light Source Medical Personnel Protection Interlock

\author{
Scott Buda \\ Nicholas F. Gmür \\ Robert Larson \\ William Thomlinson \\ National Synchrotron Light Source \\ Brookhaven National Laboratory, P.O. Box 5000 \\ Upton, NY 11973-5000
}

November 1998

BROOKHAVEN NATIONAL LABORATORY

BROOKHAVEN SCIENCE ASSOCIATES

Under Contract No. DE-ACO2-98CH10886 with the

UNITED STATES DEPARTMENT OF ENERGY 
DISCLAIMER

This report was prepared as an account of work sponsored by an agency of the United States Government. Neither the United States Government nor any agency thereof, nor any of their employees, nor any of their contractors, subcontractors, or their employees, makes any warranty, express or implied, or assumes any legal liability or responsibility for the accuracy, completeness, or usefulness of any information, apparatus, product, or process disclosed, or represents that its use would not infringe privately owned rights. Reference herein to any specific commercial product, process, or service by trade name, trademark, manufacturer, or otherwise, does not necessarily constitute or imply its endorsement, recommendation, or favoring by the United States Government or any agency, contractor or subcontractor thereof. The views and opinions of authors expressed herein do not necessarily state or reflect those of the United States Government or any agency, contractor or subcontractor thereof. 


\section{DISCLAIMER}

Portions of this document may be illegible in electronic image products. Images are produced from the best available original document. 
BNL-47681-98/11-Rev.

INFORMAL REPORT

\title{
National Synchrotron Light Source Medical Personnel Protection Interlock
}

\author{
Scott Buda \\ Nicholas F. Gmür \\ Robert Larson \\ William Thomlinson \\ National Synchrotron Light Source \\ Brookhaven National Laboratory, P.O. Box 5000 \\ Upton, NY 11973-5000
}

November 1998

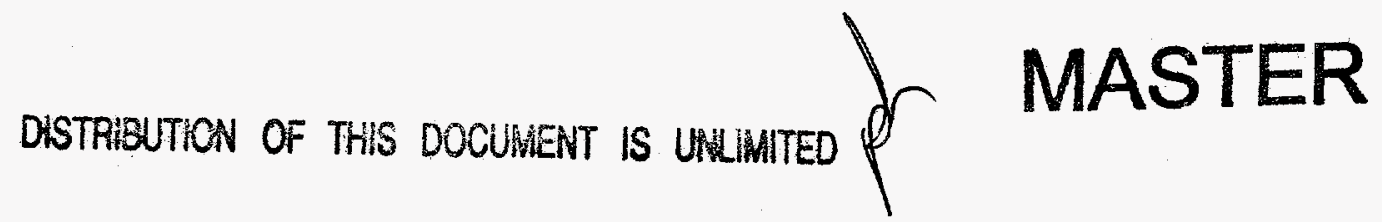




\section{Table of Contents}

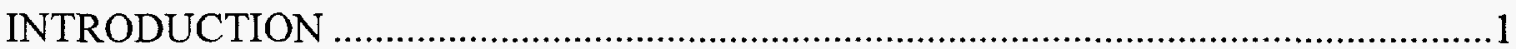

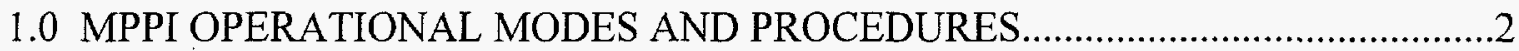

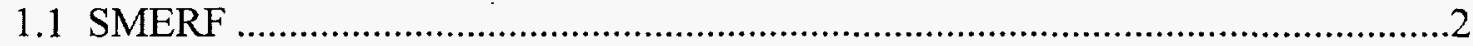

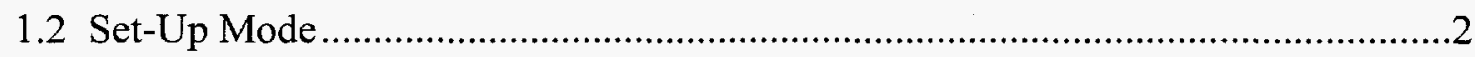

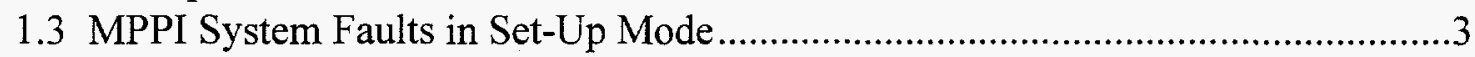

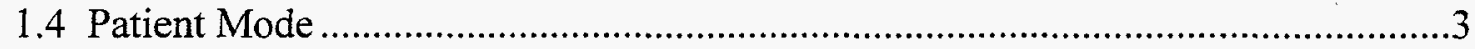

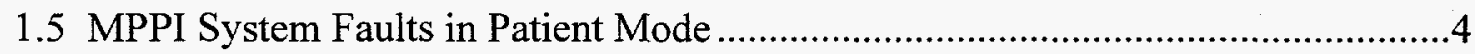

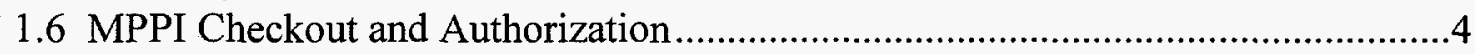

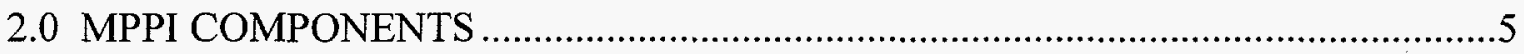

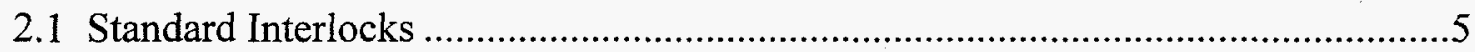

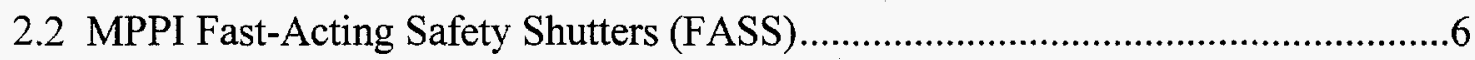

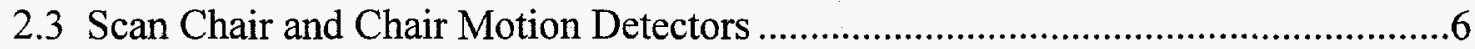

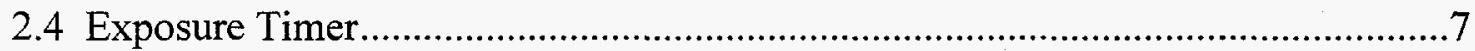

2.5 MPPI Digital and Relay Racks …….............................................................

2.6 Physician's Control Panel with Scan Switch \& Emergency Stop Buttons ...............7

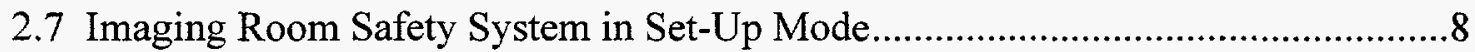

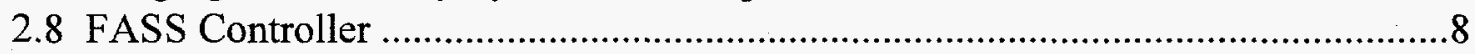

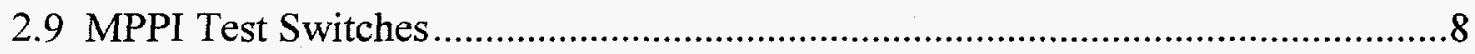

3.0 MPPI SHUTTER CONTROL AND INTERLOCKING LOGIC .................................

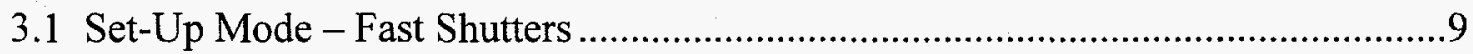

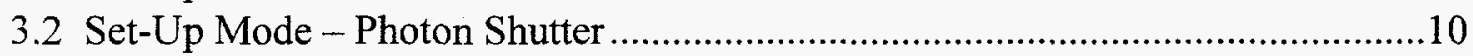

3.3 Patient Mode - Fast Shutters ........................................................................

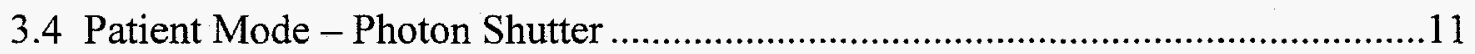

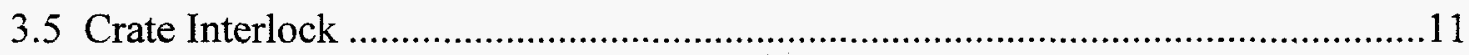

4.0 MPPI CONTROL AND FAULT LOGIC SPECIFICATIONS ……........................12

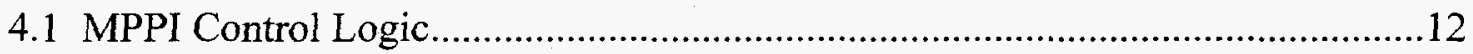

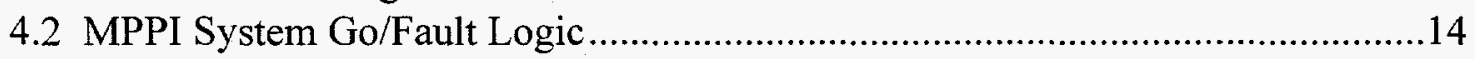

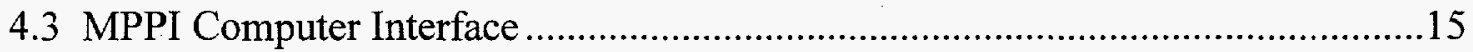

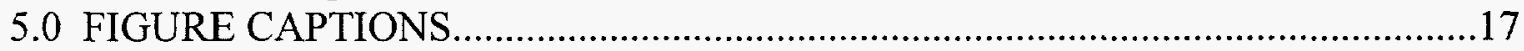

6.0 APPENDIX 


\section{INTRODUCTION}

This report is founded on reports written in April 1987 by Robert Hettel for angiography operations at the Stanford Synchrotron Research Laboratory (SSRL) and a subsequent report covering angiography operations at the National Synchrotron Light Source (NSLS); BNL Informal Report 47681, June 1992. The latter report has now been rewritten in order to accurately reflect the design and installation of a new medical safety system at the NSLS X17B2 beamline Synchrotron Medical Research Facility (SMERF). Known originally as the Angiography Personnel Protection Interlock (APPI), this system has been modified to incorporate other medical imaging research programs on the same beamline and thus the name has been changed to the more generic Medical Personnel Protection Interlock (MPPI). This report will deal almost exclusively with the human imaging (angiography, bronchography, mammography) aspects of the safety system, but will briefly explain the modular aspects of the system allowing other medical experiments to be incorporated.

The imaging process involves scanning a patient up and down through dual fixed-position $\mathrm{x}$-ray beams using a vertically translating patient chair. Exposure of the patient to $x$-rays is controlled by opening and closing a Fast-Acting Safety Shutter (FASS) at precise times in relation to the up and down motion of the scanning patient chair. The FASS is the primary. radiation-stopping element protecting the patient while the chair is at rest and while it is reversing directions during the scan. Its fail-safe and rapid operation is essential for the safety of the patient.

The NSLS/BNL requirement for redundancy in radiation safety systems dictates that there must actually be two independent shutters protecting the patient, each one capable of stopping the $\mathrm{x}$-ray beam. The redundant FASS also qualify as the primary radiation safety device, allowing emergency access to the patient Imaging Room in each of the two operating modes, Set-Up and Patient, as long as the area is configured and certified for patient imaging.

Operation of X17B2 as a human subject imaging station necessitates the implementation of a personnel protection interlock system that, in conjunction with the FASS, will:

1. Permit safe access to the patient imaging room while the synchrotron radiation beam is illuminating the upstream dual energy monochromator (to preserve the thermal stability of the monochromator);

2. Allow a patient to be imaged by the monochromatized beams under the supervision of a Responsible Physician, with scan chair motion and precision shutter actuation regulated by an imaging control computer, while providing a suitable number of safeguards against accidental radiation exposure;

3. Have different modes of operation to accommodate a) equipment set-up, test, and calibration (Set-Up Mode); and b) patient imaging (Patient Mode);

4. Ensure the quick extinction of the beams if a potentially unsafe condition is detected by the safety system.

The interlock system that performs these safety functions is called the Medical Personnel Protection Interlock (MPPI).

This MPPI report is organized such that the level of detail changes from a general overview to detailed engineering drawings of the hardware system. The general overview is presented in Section 1.0, "MPPI Operational Mode and Procedures". The various MPPI components are described in detail in Section 2.0. Section 3.0 presents some simplified logic diagrams and accompanying text. This section was written to allow readers to become familiar with the logic system without having to work through the entire set of detailed engineering drawings listed in the Appendix. Detailed logic specifications are given in Section 4.0. The Appendix also contains copies of the current MPPI interlock test procedures for Setup and Patient Modes 


\subsection{MPPI OPERATIONAL MODES AND PROCEDURES}

\section{I SMERF}

The principal components of the X17B2 MPPI are described in the following sections. Figure 5.1 shows the overall floor plan of the NSLS. The areas requiring interlocks for radiation protection consist of the Monochromator Hutch and the Imaging Room in SMERF (Fig. 5.2). The Monochromator Hutch contains the dual energy monochromator, the FASS used to control beam exposure, the photon shutter, slits, beam filters and ion chambers. The Imaging Room is the patient exposure area and contains the patient scanning chair and the detector system. A set of slits mounted in the Monochromator Hutch wall allow beam to enter the Imaging Room when the photon shutter and FASS are open.

\subsection{Set-Up Mode}

Set-Up Mode is provided so that equipment set-up, alignment, calibration, etc., with beam and without a patient present may be carried out without having to satisfy the complete Patient Mode interlock. Switching between Set-Up and Patient Modes is accomplished with a mode keyswitch in the MPPI Relay Crate. The key is stored in the Control Room Key Safe. An Operations Coordinator is called to make switches between Set-Up and Patient Modes.

In Set-Up Mode, a Monochromator Hutch search is first carried out. Section 2.1 describes the operations necessary to interlock and to allow beam into the Monochromator Hutch. It is very important to realize that at no time, in either Set-Up or Patient Mode, can the beamline front-end Small Transport Enclosure Safety Shutter (STRESS) be opened from a closed state without the Monochromator Hutch photon shutter being closed. Once the Monochromator Hutch is interlocked, with or without beam on the monochromator, the Imaging Room search sequence is as follows:

1.2.1 The doors to the Reception(2) and Fluoroscopy Rooms(2) must be closed and locked from inside the Imaging Room with Kirk keys. These keys are then placed in a key exchange unit located in the Physician Room.

1.2.2 The Imaging Room is searched and a searchbutton, located on the wall at the rear of the patient chair in the Imaging Room, is pressed. This starts a Search Timer such that the door to the Physician Room must be closed before the time runs out $(15 \mathrm{sec}$.). The Imaging Room lights are automatically turned off and a red warning light is turned on during this Search Timer period.

1.2.3 After exiting the Imaging Room and closing the door to the Physician Room, a second search button, located in the Physician Room, is pressed. This search button must also be pressed before the Search Timer period runs out. An audible alarm then sounds for a further 15 seconds.

1.2.4 If the Physician Room door has been closed and the second search button pressed in time, the termination of the Search Timer period will complete the search sequence. The Imaging Room interior lights come back on at the end of the search period. While the audible alarm sounds, the Physician Room door is locked with a Kirk key. This key is then inserted in the key exchange unit. The left-most key is rotated $1 / 2$ turn clockwise to rotate all keys. This releases the right-most key which may then be transferred to the Solenoid Release Unit where the key is turned, thus enabling the Scan Switch and photon shutter operation. All Physician Room key exchanges must take place or else the Scan Switch will not be enabled.

1.2.5 To enable the opening of the FASS, the photon shutter must first be opened by pressing the Scan Switch (hold for at least 2 seconds) located at the Physician's Panel. The photon shutter will open only if the FASS are closed. A latching circuit maintains the Scan Switch On condition (indicated by Physician Control Panel Scan Switch Active lights) and the button itself may be released. 
1.2.6 If all interlocks are properly satisfied the Physician's Panel will display a "Go" light for the Interlock Go/Fault display and the Scan Switch Enable and Active Lights (one for each logic circuit A and B) will go on. The FASS may then be opened under computer control.

1.2.7 The system will be reset to its unsearched state and disable the opening of the shutters after an MPPI fault or after opening any of the Imaging Room doors after the search sequence is completed. In either case, the search sequence must then be repeated to re-enable the shutters.

1.2.8 Normal closure of the photon shutter is done by pressing the Photon Shutter Close Button on the X17B2A Control Panel. If the FASS are open, they will also close.

\subsection{MPPI System Faults in Set-Up Mode}

1.3.1 The Emergency Stop buttons on the Physician Control Panel (1) or in the Imaging Room (2) are pressed;

\subsubsection{Any Imaging Room door is opened when the FASS are not closed;}

1.3.3 An RF Trip Reachback circuit will dump the $\mathrm{x}$-ray ring if the photon shutter is told to close and does not do so within $2 \mathrm{sec}$.

Fault logic is implemented redundantly. MPPI faults cause the FASS and the photon shutter to close. MPPI faults are latched and must be reset by a trained X17B2 beamline operator using an MPPI interlock reset key. NSLS interlock faults (Emergency Stop buttons) are also latched and must be reset by an NSLS Operations Coordinator.

Faults from other MPPI system interlocks which are active in Patient Mode (Scan Switch Interlock, Chair Motion Interlock, Exposure Timer Interlock, Clock Interlock, Logic Interlock) are bypassed when in SetUp mode. However, the Go/Fault status for these interlocks (non-latched in this mode) continues to be displayed for diagnostic purposes.

\subsection{Patient Mode}

In Patient Mode it is assumed that a person will be seated in the patient scanning chair and subjected to beam exposure. Normally the Monochromator Hutch is secured and the STRESS is opened long before the patient scan so that the monochromator crystals can reach thermal equilibrium in the beam. The closed FASS and photon shutter prevent beam from entering the Imaging Room during this time. The STRESS shutter cannot be opened from a closed state unless the Monochromator Hutch photon shutter is closed; once the STRESS is open, both the photon shutter and the FASS maybe opened under MPPI supervision.

The FASS are used to control the beam exposure received by the patient during an imaging scan. The shutters are opened and closed at precise times under computer control in relation to the up/down motion and position of the scan chair. The computer-generated shutter open requests are received by the MPPI system. The shutters will open only if enabled by the MPPI.

Several conditions must be met before the MPPI will enable the opening of the FASS:

1.4.1 In Patient Mode the doors to the Fluoroscopy, Reception and Physician Rooms must be closed (they are not locked with Kirk keys). All Kirk key locks have bolt arrests installed. The doors into the Imaging Room from both the Reception and Fluoroscopy Rooms are locked only from the outside by means of the normal tumbler door locks. That allows immediate egress from the Imaging Room, but prevents inadvertent entry into the Imaging Room. Redundant door micro-switches sense the closed position. The door between the Physician's Room and the Imaging Room is not locked from either side. This allows quick entry into the Imaging Room in case of a patient emergency. 
1.4.2 Once the Imaging Room is cleared of personnel by the Physician, a Search Timer in the Imaging Room must be started with a key available to the Physician (issued by a trained X17B2 beamline operator). Following activation of the Search Timer, the room must be cleared and the door to the Physician's Room closed in less than $60 \mathrm{sec}$. A second keyswitch located on the Physician's Control Panel must then also be turned with the same key to complete the search interlock (this is only done immediately prior to imaging). The Panel is located just outside the Imaging Room door in the Physician's Room. There is no preset time interval between the two keyswitch actions.

1.4.3 Within $15 \mathrm{sec}$. after the second keyswitch is activated, the hand-held Scan Switch pushbutton must be pressed and held depressed by the physician for the duration of the image scan procedure. This action opens the photon shutter and enables the FASS.

1.4.4 The scan chair must be moving faster than a preset speed (to prevent radiation overexposure of the patient). The preset chair speed is authorized by the Responsible Physician.

1.4.5 The Exposure Timer must be active. The Exposure Timer is triggered by the first computergenerated FASS open request if the Search Timer has terminated and the Scan Switch is on. The timer is non-retriggerable by subsequent shutter open requests until a new scan cycle has been initiated with the keyed Search Timer. The Exposure Timer period sets an overall limit to the time available to perform a patient imaging scan before the scan sequence must be re-initiated with the Search Timer. The Exposure Timer period is preset to a value authorized by the Responsible Physician and is determined from calculations of worst case exposure. Completion of the Exposure Timer period disables the opening of the FASS.

1.4.6 No MPPI faults can be present.

\subsection{MPPI System Faults in Patient Mode}

1.5.1 The Emergency Stop buttons are pressed, even if no scan is in progress. The buttons are located on the Physician's Control Panel (1) and in the Imaging Room (2).

1.5.2 Any of the Imaging Room doors are opened when the FASS are not closed.

\subsubsection{The Scan Switch is released when the FASS are not closed.}

1.5.4 The scan chair is not moving faster than the preset speed when the FASS are not closed. To avoid a fault, the shutters must be closed during the periods that the chair is slowing down, reversing direction, and speeding up.

1.5.5 The Exposure Timer is not active when the FASS are not closed. To avoid a fault, the patient imaging scan sequence must be complete before the Exposure Timer times out.

1.5.6 The internal clock for either of the redundant circuit boards in the Digital Crate ceases to function.

\subsubsection{The MPPI detects an internal logic fault (Section 4.0).}

1.5.8 An RF Trip Reachback circuit will dump the x-ray ring if the photon shutter is told to close and does not do so within $2 \mathrm{sec}$.

An MPPI fault causes both FASS and the photon shutter to close. Faults are latched and must be reset by a trained X17B2 beamline operator using an interlock reset key.

\subsection{MPPI Checkout and Authorization}

Before X17B2 is authorized for operation in Set-Up and Patient Modes, the interlocks and MPPI must have been subjected to inspection and checkout by qualified members of the NSLS safety staff. This occurs 
every six months. MPPI system checkouts must also occur after any changes have been made to the MPPI electronics.

The MPPI checkout is performed according to written test procedures (see Section 6.0 - Appendix) and verifies that all interlock components are physically intact, electrically and mechanically operational, and that the interlock functions according to specification. A full check for redundancy of the MPPI fault and operational logic is performed. In addition, more frequent but less complete system check-outs may be required during the course of a patient imaging experimental run.

The minimum Chair Speed and Exposure Timer period are specified by the Responsible Physician, and the MPPI circuits are adjusted to conform to these specifications. The MPPI settings are verified empirically by measuring the chair speed and Exposure Timer period with instruments independent of the MPPI.

\subsection{MPPI COMPONENTS}

\subsection{Standard Interlocks}

In order to enable the X17B2 beamline, the X17B line must be configured in a specific mode with operational control transferred to the X17B2 control panel. This can only occur when:

a) the X17 Transport Hutch has been searched and interlocked;

b) the X17B1 backstop is in the full out position;

c) the X17B1 Hutch has been searched and interlocked;

d) the X17B lockout key must be inserted and rotated in its Kirk Key Solenoid Release Unit (SRU);

e) all cooling water and vacuum system user interlocks are satisfied.

A standard NSLS safety system is used to control and safeguard access to the Monochromator Hutch. The interlock ensures that the STRESS is closed before the door can be unlocked and opened, and that the Monochromator Hutch has been searched, doors closed and locked before the STRESS can be opened. A further requirement for opening the STRESS is that the photon shutter be closed.

Keys from the doors that are interlocked must be inserted and rotated in appropriate Solenoid Release Units (SRU's) before STRESS opening is enabled. The SRU's hold the keys captive while the STRESS is open; the door deadbolts hold the keys captive while doors are open. In addition to this mechanical interlock, the interlock system implements a redundant electrical interlock using switches that sense the closed status of doors and shutters (two independent status switches per element).

An interlock fault is generated if the Monochromator Hutch door status switch indicates "not closed" when the STRESS status switch indicates "not closed". This interlock fault extinguishes stored beam in the NSLS X-ray storage ring. Faults are latched by the X17 interlock system, and must be reset by an NSLS Operations Coordinator.

Two emergency stop buttons, located in the Monochromator Hutch, will also dump the x-ray storage ring beam if pressed while the STRESS is open. Emergency stop buttons in the Imaging Room(2) as well as on the Physician's Control Panel(1) prevent photon beams from entering the Imaging Room, but do not drop out the storage ring.

The Monochromator Hutch can be operated in two different modes, ANGI and MECT. In ANGI mode, the backstop is Kirk-keyed in the up position and the Photon Shutter/FASS assembly is Kirk-keyed in the up and angled position. The ANGI Kirk keys are removed from their locks, inserted and turned (thus 
captured) in the ANGI key exchange unit. In MECT mode, the backstop is Kirk-keyed in the down position and the Photon Shutter/FASS assembly is Kirk-keyed in the down and flat position. The MECT keys are removed from their locks, inserted and turned (thus captured) in the MECT key exchange unit. These two modes also control the action of the Direct Beam Stop (DBS) located in the X17 Transport Hutch section of the beamline. In ANGI mode, the DBS is down allowing passage of the white beam. In MECT mode, the DBS is up blocking the white beam and allowing passage of the monochromatic MECT beam.

\subsection{MPPI Fast-Acting Safety Shutters (FASS)}

Two independently-acting Fast Shutters, when they are closed, prevent radiation from reaching the Imaging Room. Each one is capable of stopping full monochromatic beam; two are provided to satisfy the requirement for redundancy in radiation safety systems. The shutters are actuated simultaneously but independently.

Each shutter consists of a pair of "vanes" (2.25mm thick tungsten alloy, min. density $17 \mathrm{~g} / \mathrm{cc}$; SLS-92.1074-2) that rotate around a horizontal axis that is perpendicular to the incoming beam to produce a "venetian blind" shuttering effect (Fig. 5.3a and 5.3b). That is, beam strikes an upstream vane, then a downstream vane, each at a $45^{\circ}$ angle, when the shutter is closed; beam passes unobstructed between the vanes when the shutter is rotated by $45^{\circ}$ to its open position.

Each shutter assembly rotates open and closed through the actuation of a pair of spring-loaded rotary solenoids, one solenoid at each end of the assembly. The solenoids must be powered on to open the shutter, and the shutter will close by spring action when power is removed, thus providing fail-safe operation. Closure time from full open is less than $40 \mathrm{msec}$ once power to the solenoid has been removed. The rapid action of the FASS enables them to be used to precisely control exposure during the imaging scan and to quickly extinguish beam if an unsafe condition is detected by the MPPI (in comparison, it takes somewhat less than $300 \mathrm{msec}$ to extinguish the stored beam in the NSLS x-ray ring after a conventional fault, and more than a second to close the STRESS).

Closed status for each shutter is detected redundantly by a pair of microswitches. Open status is detected non-redundantly.

The FASS open status is displayed on the Physician's Control Panel, on the FASS Controller panel and on the Patient Panel.

\subsection{Scan Chair and Chair Motion Detectors}

To prevent over-exposing the patient to radiation, it is essential that the patient scan chair be moving up or down at a speed greater than a certain preset value before the FASS are allowed to open. Also, if the shutters are open, they must be made to close if the chair speed should drop below the minimum value. For this reason, the scan chair is equipped with a redundant pair of linear encoders that sense the speed of up or down motion during a scan.

As the chair moves up or down, the output pulse rate from each encoder is detected by the MPPI. The rates from both encoders must exceed a certain preset rate before the MPPI permits the FASS to open. The minimum rate in $\mathrm{cm} / \mathrm{sec}$, is set redundantly with a pair of thumbwheel switches located behind a locked transparent door on the front panel of the MPPI Status Panel. The minimum rate is authorized by the Responsible Physician.

Circuitry is incorporated to detect changes in chair direction, together with a "chatter filter" that insures that the chair is moving at a speed higher than the minimum set value for a preset number of encoder pulse cycles before valid chair motion is indicated. Whereas a number of pulses are required to "fill" the chatter filter counter and establish a valid motion indication, only one low rate pulse cycle or one oppositely phased direction sequence will reset the counter, yielding a no-motion indication. The chatter filter count for each redundant circuit is preset with board-mounted switches inside the MPPI Digital Crate. 


\subsection{Exposure Timer}

The overall time period from the moment the imaging control computer issues the first request to open the FASS at the beginning of a sequence of scans to the moment the shutters close for the last time at the end of the last scan in the sequence is limited by the MPPI Exposure Timer. The timer is implemented redundantly with the period set to a value authorized by the Responsible Physician. The timer period is determined from calculations of worst case exposure for NSLS beam and imaging scan parameters. The redundant timers are set with a pair of thumbwheel switches located behind a locked transparent door on the front panel of the MPPI Status Panel.

\subsection{MPPI Digital and Relay Crates}

The MPPI control and fault logic is implemented within a pair of interconnected crates. One crate contains relay circuitry, the other contains solid state (TTL and CMOS) digital circuitry. The Relay and Digital Crates are located in a rack in the X17B2 Medical Computer Room. System status is indicated by lights on the front panels of these crates.

In keeping with NSLS interlock design standards, MPPI circuitry is implemented with electromechanical relays wherever possible. Because of the need for fast response times, the chair motion detection circuitry is configured using solid state components, and solid state relays are used in series with the electromechanical relays to interrupt power to the FASS solenoids in case of a chair motion fault (Section 2.3).

System timers and the control/status interface with the imaging control computer (Section 4.3) are also implemented in the Digital Crate. Redundancy in the Digital Crate is provided where needed by supplying independent circuit boards, each channel with its own isolated power supply, on which parallel-acting redundant circuits can be configured. As a safeguard against unpredictable failure modes of the digital circuitry, a Logic Interlock is provided in the Relay Crate that checks for disagreement between critical signals coming from the redundant digital circuits (Section 4.2.6).

\subsection{Physician's Control Panel with Scan Switch \& Emergency Stop Buttons}

A Physician's Control Panel is located just outside the Imaging Room door in the Physician Room. A hand-held pushbutton Scan Switch assembly is attached to the Physician's Control Panel by a short cord. The physician initiates a patient imaging scan with a search key which activates a keyswitch mounted on the panel. This same key was used in an Imaging Room keyswitch to initiate a search of that room. Use of the key in the Control Panel switch completes the sequence and starts the scan timer. Within the $\sim 15$ second period, the physician must depress the Scan Switch button. The physician must keep the Scan Switch button depressed during the entire scan to open the photon shutter and to permit the opening of the FASS by computer command. The short cord enables the physician to move within a limited distance from the Control Panel during the scan. In particular, the physician may move close to the window for observation of the patient. Release of the Scan Switch during the imaging procedure always necessitates a re-enable by the start search key. If the Scan Switch is released while the FASS are open, a latched system fault and closure of the FASS and photon shutter occur. A trained X17B2 beamline operator must reset the system in that case.

Also mounted on the Physician's Control Panel are indicators displaying Computer Ready, Search Complete, Interlock Go, and Exposure Timer On Status. In addition, the Photon Shutter and Fast-Acting Safety Shutter open lights are illuminated during those parts of the cycle when the Photon Shutter and FASS are open.

An Emergency Stop button is mounted on the Physician's Control Panel that will cause a latched system fault and close the FASS and photon shutter when pressed. 


\subsection{Imaging Room Safety System in Set-Up Mode}

When the Imaging Room is configured for patient imaging (Patient Mode), but is switched into Set-Up mode, a search must be performed in the room before the photon shutter and FASS can be opened. Details of this mode and the search procedure are given in Section 1.2.

\subsection{FASS Controller}

The Fast Shutter Controller chassis receives open/close command signals for the two FASS Fast Shutters from the MPPI Relay Crate and switches power to the shutter solenoids in response.

To open each shutter rapidly against the strong spring force required for fast closure, 50 volts DC is applied momentarily to its solenoid pair. When the shutter is fully open, as detected by an open status switch, the solenoid voltage is dropped to a holding level of 24 volts DC. Because the solenoids can be damaged if 50 volts is applied for a prolonged period, a timeout circuit is included for each shutter that automatically cuts all power to its solenoids if the proper open status that switches off the 50 volts is not detected within $\sim 1$ second.

Front panel indicators for the Fast Shutter Controller include shutter open status, open command, 50 volt timer status, and power on status for the three monitored power supplies.

\subsection{MPPI Test Switches}

Several test switches are included in the MPPI to facilitate redundancy checking. Most of these are inserted in series with redundant system switches or other components that are activated simultaneously during normal operation and are difficult to manipulate individually for testing purposes. The series type test switches are fail-safe in the sense that they must be closed-circuited for normal operation and leaving one in the open-circuit state simply inhibits one chain of the Fast Shutter open enable logic. Series test switches include:

a) FS1 and FS2 Open Permit Switches

b) FS1 and FS2 Open Request Switches

c) A and B Scan Test Switches

d) A and B Emergency Stop Switches

e) A1, B1, A2, B2 Clock Enable Active/Bypass Switches

In addition to the series test switches, parallel test switches have been installed to bypass interlock components that may lead to inconclusive results during testing. The bypass test switches are not inherently fail-safe: leaving one in the bypassed state defeats the safety action of the bypassed component. For this reason, bypass switches are only installed on components that have separate backup counterparts so that a safety interlock is never entirely defeated by leaving a switch in bypass mode (indeed it is the redundant backup feature that leads to inconclusive testing and the need for bypass switches in the first place). Also, the bypass switching is arranged so that the Photon Shutter Open Enable (Section 4.1.4) is inhibited and the shutter is forced to close, and a flashing red light on the front of the Patient Panel is activated when any of these switches is in bypass mode.

The MPPI bypass switches include (see Section 4.0 for logic specifications):

a. Fast Shutter 1 Fast Permit bypass (to bypass Chair Motion Interlock A configured in solid state logic in order to test relay-configured interlock); 
b. Fast Shutter 2 Fast Permit bypass (to bypass Chair Motion Interlock B configured in solid state logic in order to test relay-configured interlock);

c. Logic Interlock bypass (so that tests for redundancy in causing shutter closure by manipulation of the Fast Shutter 1 and 2 Open Requests and Fast Permits, and by faulting the chain A and B Exposure Timer and Chair Motion Interlocks, will not also cause shutter closure through the simultaneous generation of Logic Interlock faults).

As a final safeguard against leaving switches in bypass mode, the states of the bypass switches and the functionings of the bypassable components are tested during the MPPI Test Procedures (see Section 6.0 Appendix). The switches are secured behind a latched door at the end of the authorizing procedure.

\subsection{MPPI SHUTTER CONTROL AND INTERLOCKING LOGIC}

\subsection{Set-Up Mode - Fast Shutters}

A simplified logic diagram for the Fast-Acting Safety Shutters and Photon Shutter is shown in Figure 5.4. The logic is shown for Fast Shutter 1(FS1) and the Photon Shutter. The circuit for Fast Shutter 2(FS2) is identical to that for FS1. A description of the logic follows below.

In order for the FS1 to open, FSI OPEN COMMAND must be true. All inputs to the final AND gate (lower right) must be true. One of the three conditions is that the SUM GO A signal be true, indicating that no faults exist. The SUM GO A signal is composed of the state of the DOOR INTERLOCK and the EMERGENCY STOP button not depressed.

The OPEN PERMIT signal requires that:

DOORS ARE CLOSED

SCAN SWITCH IS ON

PHOTON SHUTTER IS OPEN

To understand the SCAN SWITCH operation, refer to the lower left on Figure 5.4. The sequence of events is as follows. A standard search of the Imaging Room is done as described in Section 1.0 above. At the completion of this procedure the personnel exit the Imaging Room through the Physician's door, closing it behind them. This puts a TRUE condition on the DOORS A input to the FSI OPEN PERMIT AND gate (center). At this time the IMAGING ROOM SEARCH COMPLETE-B2 coming from the B2 hutch logic is pulled true, generating a 1 second pulse, B2-SEARCH COMPLETE A. This pulse travels through an OR gate to the input of a 2 input AND gate. The B2 hutch logic also sends a second signal, HUTCH SECURE-B2 to an AND gate. Since there are no faults, the SUM GO A signal is true, and in addition the doors are closed, resulting in the third TRUE input to this gate. The output of this gate is fed to a second AND gate, and combining with the OR gate output, pulls the SEARCHED LATCHED line true. This is fed back through the OR gate to maintain itself, even after the 1 second pulse is over. The SEARCHED LATCHED signal is sent to yet another AND gate. The other input to this gate is derived from pressing the SCAN SWITCH button. The output of this gate is fed to the SCAN SWITCH ON A OR gate. The output of this OR gate is fed back and in conjunction with the PHOTON SHUTTER OPEN STATUS signal maintains the SCAN SWITCH ON A even after the button is released. The button also serves to open the PHOTON SHUTTER (see below), and must be held down while the PHOTON SHUTTER actually opens, a few seconds.

This effective latching of the SCAN SWITCH ON A line is a major difference between the PATIENT and SETUP modes.

At this point the FS1 OPEN COMMAND gate is primed and now needs only the FS1 OPEN REQUEST signal from the computer to actually drive the FS1 shutter to the open position. The FS2 drive signal is derived in an identical manner, giving a redundant system for beam control. 


\subsection{Set-Up Mode - Photon Shutter}

The upper right section of Figure 5.4 shows the logic for the operation of the PHOTON SHUTTER. It is opened by the action of the SCAN SWITCH ON (A \& B). These are two of the inputs to the AND gate which drives the OPEN PHOTON SHUTTER line. The other two inputs come from two AND gates. One input to each of these gates is SUM GO A or SUM GO B, indicating that no faults are present in the system (see description of the SUM GO signals in Section 3.1). The other inputs to these gates are fed from an AND/OR gate combination. The AND gate in this group ensures that the Photon Shutter can only be opened when all the FAST SHUTTERS (FS1 \& FS2) are closed, which occurs at the start of the imaging process.

Once the PHOTON SHUTTER is open, a signal indicating that it is indeed open is fed through the OR gate. This allows the FAST SHUTTERS to open and close during normal operation without closing the Photon Shutter during each cycle. Any fault will close the Photon Shutter and both Fast Shutters. (FS1 \& FS2). The normal way to close the PHOTON SHUTTER is to depress the PHOTON SHUTTER CLOSE button located on the B2 HUTCH LOGIC unit (\#X17B2A) - see Schematic 6.9. This button is only used in SET-UP mode since the PHOTON SHUTTER is closed by any release of the SCAN SWITCH in PATIENT MODE.

A PHOTON SHUTTER FAULT logic circuit has been added to the standard interlock logic on X17B2. If for any reason the PHOTON SHUTTER is told to close (such as an MPPI fault) and does not close within 2 seconds, the beam in the ring will be dumped by turning off the ring $R F$ system. This protection essentially "reaches back" into the NSLS acceleration system for personnel protection.

\section{3 patient Mode - Fast Shutters}

A simplified logic diagram for the FAST SHUTTERS and PHOTON SHUTTER is shown in Figure 5.5. The logic is shown for FAST SHUTTER 1, (FS1) and the PHOTON SHUTTER. The circuit for FAST SHUTTER 2 (FS2) is identical to that for FS1. A description of the logic follows below.

In order for the FS1 to open, FS1 OPEN COMMAND must be true. All inputs to the final AND gate which feeds the FAST SHUTTER CONTROLLER (upper right) must be true. These are:

FAST PERMIT - a chair motion OK signal which responds at microsecond speeds

SUM GO A - composed of the states of the following latched interlocks:

STOP BUTTON NOT DEPRESSED

DOORS CLOSED

SCAN SWITCH ON

CHAIR MOTION

LOGIC

EXPOSURE TIMER

ION CHAMBER

FSI OPEN PERMIT

FSI OPEN REQUEST

PHOTON SHUTTER OPEN (STATUS)

The sequence of events is as follows. The physician searches the Imaging Room and turns his/her key in a START SEARCH key receptacle. He/she then has 60 seconds to exit the room and close the Imaging Room door in order to successfully complete the search. Closing the door puts a true condition on the DOORS A CLOSED input to the FS1 OPEN PERMIT AND gate. He/she then turns the key in the SCAN TIMER KEYSWITCH on the Physician's Panel, starting the SCAN TIMER. Before this timer times out (approx. 15 seconds), the SCAN SWITCH BUTTON must be depressed, forcing the SCAN SWITCH ON A line to go true. This line will remain in a true state provided the SCAN SWITCH BUTTON is held down, by virtue of the feedback through the OR gate. 
While the SCAN SWITCH BUTTON is being held down, a computer command is issued for an FS1 OPEN REQUEST starting the EXPOSURE TIMER, which is a fifth condition on the OPEN PERMIT AND gate.

Prior to the issuing of the OPEN REQUEST the patient chair will be in cycles of up and down motion, even though the shutters are not yet open. When the chair is moving at the correct velocity during any part of a cycle, the CHAIR MOTION ON line is held true at the input to the OPEN PERMIT AND gate.

At this point all five inputs to the OPEN PERMIT gate will be true, feeding a true signal to the FS1 OPEN COMMAND gate. A FAST PERMIT FS1 signal derived from the chair motion is also fed to the OPEN COMMAND gate. Thus the FS1 OPEN COMMAND gate is primed and now needs only the FS1 OPEN REQUEST signal from the computer to actually drive the FS1 to the open position. The FS2 drive signal is derived in an identical manner, giving a redundant system for beam control.

\subsection{Patient Mode - Photon Shutter}

The upper right section of Figure 5.5 shows the logic for the operation of the PHOTON SHUTTER. It is basically opened and closed by the action of the SCAN SWITCH ON (A \& B). These are two of the inputs to the AND gate which drives the OPEN PHOTON SHUTTER line. The other two inputs come from two AND gates. One input to each of these gates is SUM GO A or SUM GO B, indicating that no faults are present in the system (see description of the SUM GO signals in Section 3.3). The other inputs to these gates are fed from an AND/OR gate combination. The AND gate in this group ensures that the PHOTON SHUTTER can only be opened when all the FAST SHUTTERS (FS1 \& FS2) are closed, which occurs at the start of the imaging process. Once the PHOTON SHUTTER is open, a signal indicating that it is indeed open is fed through the OR gate. This allows the FAST SHUTTERS to open and close during normal operation without closing the PHOTON SHUTTER during each cycle. Release of the SCAN SWITCH or any fault will close the Photon Shutter and both Fast Shutters (FS1 \& FS2).

A PHOTON SHUTTER FAULT logic circuit has been added to the standard interlock logic on X17B2. If for any reason the PHOTON SHUTTER is told to close (such as an MPPI fault) and does not close within 2 seconds, the beam in the ring will be dumped by turning off the ring RF system. This protection essentially "reaches back" into the NSLS acceleration system for personnel protection.

Note that there is only one PHOTON SHUTTER, and the circuits for the photon shutter explained above are not duplicated.

\subsection{Crate Interlock}

The logic circuits for the system are contained on a series of printed circuit boards which are installed in two crates; the Relay Crate and the Digital Crate. While the system at present operates in the MPPI mode, a second mode, MECT, will be accommodated in the near future. This change of mode is accomplished in part by removing some of the cards and inserting others which contain logic designed for the desired mode. In order to prohibit operation with an incorrect mix of cards, or cards in the wrong location, a crate interlock system is used. This is accomplished by jumpers in specific locations on each card, installed during manufacture. The jumpers are connected in a daisy-chain fashion by wiring on the rear crate connectors. This ensures that a full serial connection through all the CORRECT CARDS and in the CORRECT POSITION is established, energizing a relay that either MPPI or MECT mode is ready for operation. 


\subsection{MPPI CONTROL AND FAULT LOGIC SPECIFICATIONS}

Principal control and fault logic specifications for the MPPI system are given below.

4.I MPPI Control Logic

4.1.1 Fast Shutter Open Command (FS Op Cmcl), redundant Fast Shutters 1 and 2 (FS1 and FS2)

FS Op Cmd(1,2) = FS Open Request $(1,2)$ AND Open Permit FS(1,2)

AND FS Fast Permit(1,2) AND Sum Go(A,B)

FS Close Cmd $=\overline{\text { FS Op Cmd }}$

FS Open Request generated by imaging control computer.

4.1.2 Fast Shutter Open Permit (FS Op Perm) and Enable, redundant

FS Op Perm $(A, B)=$ Doors Closed $(A, B)$ AND Scan Switch On(A,B) AND

[Set-Up Mode(A,B) OR (Exposure Timer On(A,B) AND

Chair Motion On(A,B))] AND

Lamp Buss OK

FS Open Enable $(A, B)=F S$ Op Perm $(A, B)$ AND Sum Go A(A,B) AND

Sum Go $B(A, B)$

4.1.3 Fast Shutter Fast Permit (FS Fast Perm), redundant

FS Fast Perm $(1,2)=$ Set-Up Mode(A,B) OR [(Chair Motion On(A,B) AND Clock Intlk Go(A,B)]

Note: FS Fast Permit logic is implemented in Digital Crate and utilizes solid state relays in Relay Crate. Response time $=\sim 1 \mathrm{msec}$.

4.1.4 Photon Shutter Open Enable (Ps Op En), redundant

Ps Op En(A,B) $=[($ FS1 Closed A\&B AND FS2 Closed A\&B) OR (PS Open)]

AND Lamp Bus Go AND Logic/Fast Intlk Unbypassed

AND Sum Go A,B

\subsubsection{Scan Timer}

Start Scan Timer $=$ Summary Go A\&B AND Scan Switch Not On A\&B AND Patient Mode AND

Physician's Control Pan KeySw AND Exp Timer Not On

Stop Scan Timer $=$ Time-out OR Summary Fault $\mathbf{A}$ OR

Summary Fault B OR Scan Switch On A\&B

4.1.6 Scan Switch (Scan Sw), redundant

a. Patient Mode 
Scan $\mathrm{Sw}$ On $=$ Scan Sw On OR Scan Timer On AND Scan Sw pressed(A,B)

\section{b. Set-Up Mode}

Scan Sw Enable(A,B) = Imaging Room Searched(A,B)

Scan Sw On(A,B) = Scan Sw Enable(A,B) AND [Scan Sw(A,B)

[Scan $\operatorname{Sw}(A, B)$ momentary on $\mathbf{O R}$

(Scan Sw On(A,B) AND Photon Shutter Open(A,B))]

\subsubsection{Imaging Room Searched (Srch OK) and Search Latch, redundant}

Search Latch On $(A, B)=$ Set-Up Mode $(A, B)$ AND Summary Go(A,B) AND

B2 Hutch Secure(A,B) AND

Doors Closed(A,B) AND

[Search Complete B2(Momentary) OR Search Latch On(A,B)]

4.1.8 Exposure Timer (Exp Timer, Patient Mode only), redundant

Exp Timer On $(A, B)=$ Exp Timer triggered $(A, B)$ AND Exp Timer not timed out $(A, B)$ AND Patient $\operatorname{Mode}(A, B)$

Exp Timer Off(A,B) $=$ Exp Timer timed out(A,B) OR Set-Up Mode(A,B)

Exp Timer Trigger $(A, B)=$ FS Open Request $(1,2)$ AND Exp Timer Trigger Enable(A,B)

Trigger Enable $(A, B)=$ Scan Sw On(A,B) AND Scan Timer Off AND Exp Timer Trig Latch On(A,B)

Exp Timer Trig Latch Set(A,B) $=$ Scan Timer On AND Trig Latch Not Reset(A,B)

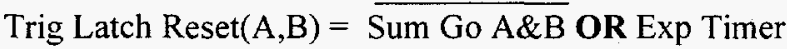
On(A,B) OR [Scan Sw A\&B Not On(A,B)

AND Scan Timer Off]

\subsubsection{Chair Motion On, redundant}

Chair Motion On $(A, B)=$ frequency coming from chair motion sensors $(A, B)$ must be greater than the preset frequency, corresponding to a minimum chair speed

\section{AND}

the chair must be moving in the same direction as determined by direction change sensing circuits $(A, B)$ FOR a preset number of pulse cycle periods as determined by the setting of the Chatter Filter $(A, B)$ - Section 2.3

\subsubsection{Logic or Fast Interlock Bypass}


Logic or Fast Intlk Bypass = Logic Intlk Bypass Sw On OR

Fast Permit 1 Bypass SW On OR

Fast Permit 2 Bypass Sw On

Note: See Section 2.9 for description of bypass switches.

4.1.11 Patient/Set-Up Mode (Pat/Set-Up Mode), redundant

Patient Mode (A,B) $=$ Pat Mode Keyed On(A,B) OR [Setup Mode(A,B) AND Scan Timer On(A,B)]

Set-Up Mode $(A, B)=\overline{\text { Patient } \operatorname{Mode}(A, B)}$

Note: The Patient Mode logic prevents key-switching to Set-Up mode if the Search Timer is on. Without this precaution it would be possible to open the FASS without chair motion, etc., if a Patient Mode scan was key-started by the physician and if the MPPI was then switched to Set-Up mode before the Search timeout. Switching from Patient to Set-Up mode during a scan after the Search timeout will close and inhibit opening of the Fast Shutters until an Imaging Room search sequence is performed (Section 1.2).

4.2 MPPI System Go/Fault Logic

All MPPI system Go/Fault logic is implemented redundantly (Chains $A$ and $B$ ). Interlock faults are latched unless they are bypassed by switching to Set-Up mode, in which case the faults are indicated but not latched and do not cause a system summary fault. Latched faults must be reset by an trained X17B2 beamline operator using the reset key.

An interlock Fault is the logical inverse of its Go condition:

Fault $=\overline{\text { Go }}$

\subsubsection{Stop Button Interlock}

Stop Button Intlk Go(A,B) $=$ Stop Button(A,B), 3 each, not pressed

\subsubsection{Imaging Room Door Interlock}

Imaging Room Door Intlk Go(A,B) = Doors Closed(A,B) OR [FS1 Closed(A,B) AND FS2 Closed(A,B)]

\subsubsection{Scan Switch Interlock}

Scan Sw Intlk Go(A,B) = Scan Sw On(A,B) OR [FS1 Closed(A,B) AND FS2 Closed(A,B)]

Note: Scan Switch Interlock is bypassed in Set-Up mode.

\subsubsection{Chair Interlock}

Chair Intlk Go(A,B) $=$ Chair Motion On(A,B) OR [FS1 Closed(A,B) AND FS2 Closed(A,B)]

Note: The Chair Motion Interlock is implemented with solid state logic in the Digital Crate as part of the shutter Fast Permit (Section 4.1.3), and with relay logic in the Relay Crate. Chair Motion Interlock is bypassed in Set-Up mode.

\subsubsection{Exposure Timer Interlock}

Exp Timer Intlk Go(A,B) = Exp Timer On(A,B) OR [FS1 Closed(A,B) AND FS2 Closed(A,B)] 
Note: Exposure Timer Interlock is bypassed in Set-Up mode.

4.2.6 Logic Interlock (Digital Panel logic check; Logic Interlock has redundant relays following the nonredundant logic given below)

Logic Intlk Go(A,B) $=[($ FS1 Fast Perm On AND FS2 Fast Perm On) OR (FS1 Fast Perm Off AND FS2 Fast Perm Off)]

AND

[(Chair Motion On A AND Chair Motion On B) OR

(Chair Motion Off A AND Chair Motion Off B)]

AND

[(Exp Timer On A AND Exp Timer On B) OR

(Exp Timer Off A AND Exp Timer Off B)]

AND

[(FS1 Open Request AND FS2 Open Request) OR

(FS1 Close Request AND FS2 Close Request)]

Note: Logic Interlock is bypassed in Set-Up mode.

4.2.7 Summary Interlock Go (Sum Go A \& B)

Sum $G o(A, B)=$ Stop Button Intlk Go(A,B) AND Door Intlk Go(A,B) AND

[Set-Up Mode(A,B) OR (Scan Sw Intlk Go(A,B) AND

Chair Intk Go(A,B) AND Exp Timer Intlk Go(A,B) AND Logic Intlk Go(A,B) AND

Ion Chamber Intlk Go(A,B))]

\subsubsection{Clock Interlock}

Clock Intlk Go(A,B) $=($ Clock A1 On AND Clock A2 On) AND (Clock B1 On AND Clock B2 On)

Note: This interlock is implemented in the Digital Crate and is part of the Fast Permit (Section 4.1.3). The interlock is bypassed in Set-Up mode.

In addition to the above redundant interlocks, a non-redundant, non-latched Lamp Buss Interlock is implemented in the MPPI. The Lamp Buss interlock ensures that one or more of the steering diodes used to direct power from the Lamp Test Buss to system interlock and status indicator lights is not short circuited. Such a short could put power on the Lamp Buss when it was not intended. A Lamp Buss Fault causes the FASS and Photon Shutter to close.

\subsubsection{Lamp Buss Interlock, non-redundant}

Lamp Buss Intlk Fault = Lamp Test button not pushed AND $+24 \mathrm{~V}$ power on Lamp Test Buss

4.3 MPPI Computer Interface

The imaging control computer monitors MPPI system status and transmits the request to open FASS

FS1 OPEN REQUEST 
FS2 OPEN REQUEST

via a CAMAC digital input/output register (Kinetic Systems IGOR 3060) that interfaces directly to the MPPI Digital Crate. Monitored status includes:

\subsubsection{Photon Shutter opened and closed status;}

4.3.2 Fast Shutter Open Enable;

4.3.3 Fast Shutters 1 and 2 open and closed status;

4.3.4 Summary Interlock Go/Fault status;

4.3.5 Patient/Set-Up mode.

\section{ACKNOWLEDGMENTS}

Contributors to the conceptual SSRL design of the APPI system include J. Cerino and R. Yotam from SSRL; G. Warren and K. Crook from SLAC; J. Otis, H. Zeman, and B. Hughes from Stanford University; and A. Thompson, C. Pike, A. Turney, C. Sealy, and J. Henderson from Lawrence Berkeley National Laboratory. Contributors to the implementation of the APPI system at SSRL include J. Otis, A. Thompson, and H. Zeman from the Angiography research team; D. Horelick from SLAC; C. Troxel, R. Filippi, and the operators of the SSRL Operations group; and R. Ortiz, J. Hood, L. Martin, S. Avery, and M. Horton from the SSRL Electronics group.

At the NSLS, contributions to the design and implementation of the MPPI system came from R. Best, S. Buda, W. Case, T. Dickinson, M. Hughes, R. Larson and T. Monahan. 


\subsection{FIGURE CAPTIONS}

5.1 NSLS Experimental Floor with SMERF Highlighted

5.2 Synchrotron Medical Research Facility (SMERF) in Detail

5.3a MPPI Fast-Acting Safety Shutter - Front View (SLS-92.107-1-5)

5.3b MPPI Fast-Acting Safety Shutter - Side View (SLS-92.107-1-5)

5.4 MPPI Set-Up Mode - Logic Diagram (SLS-60.620-1-4, Rev. B)

5.5 MPPI Patient Mode - Logic Diagram (SLS-60.619-1-4, Rev. B) 


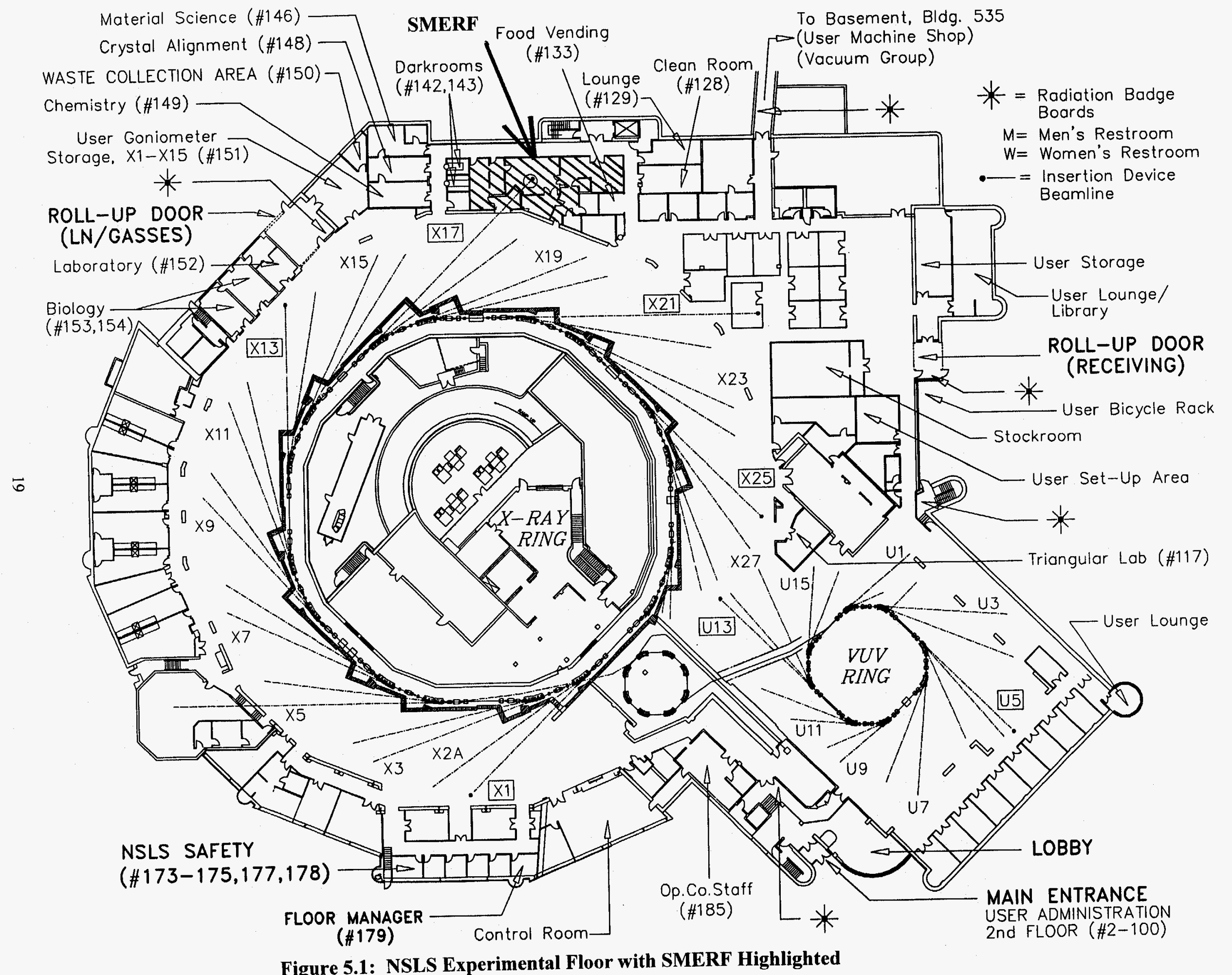




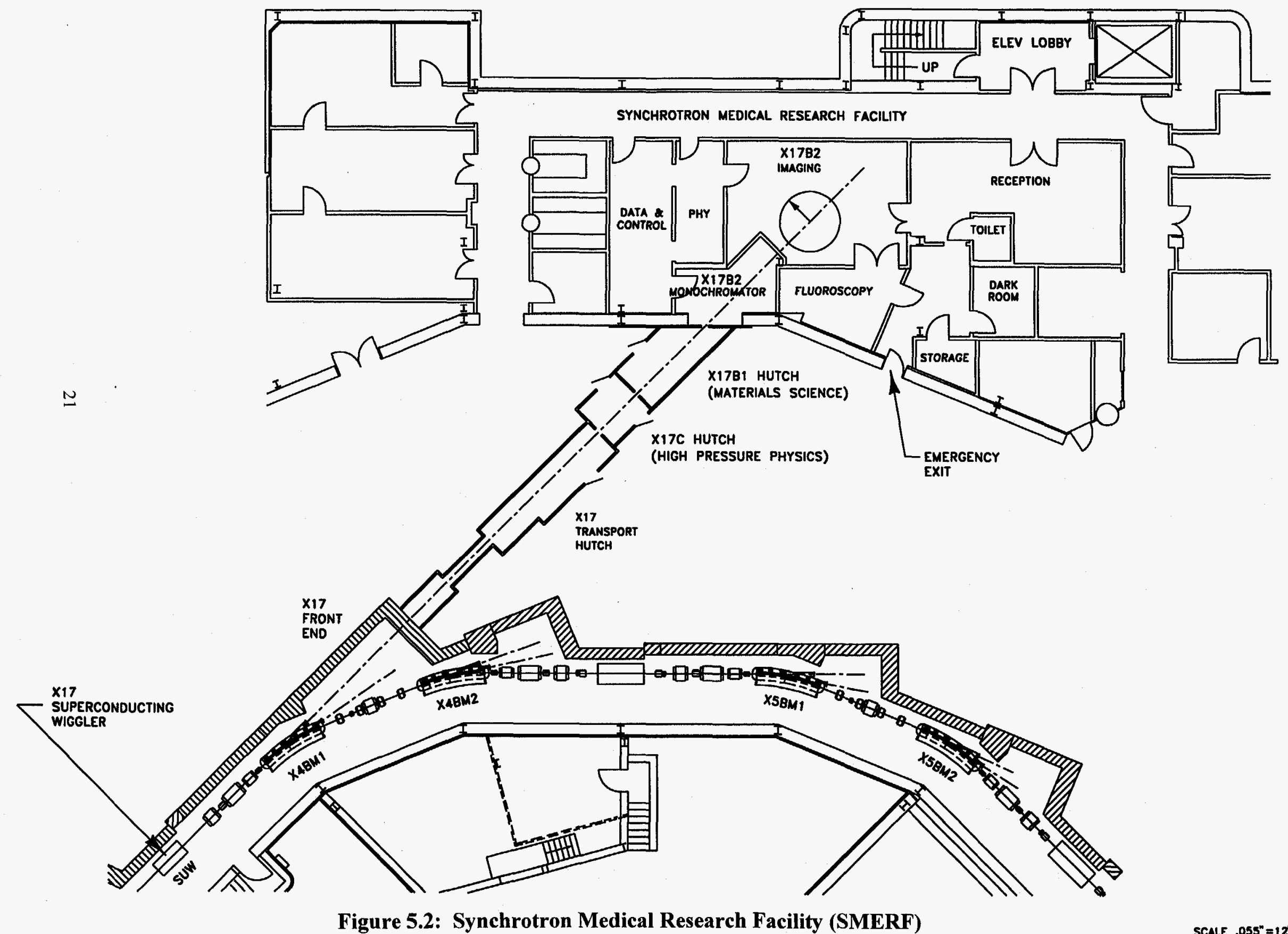

Figure 5.2: Synchrotron Medical Research Facility (SMERF) 


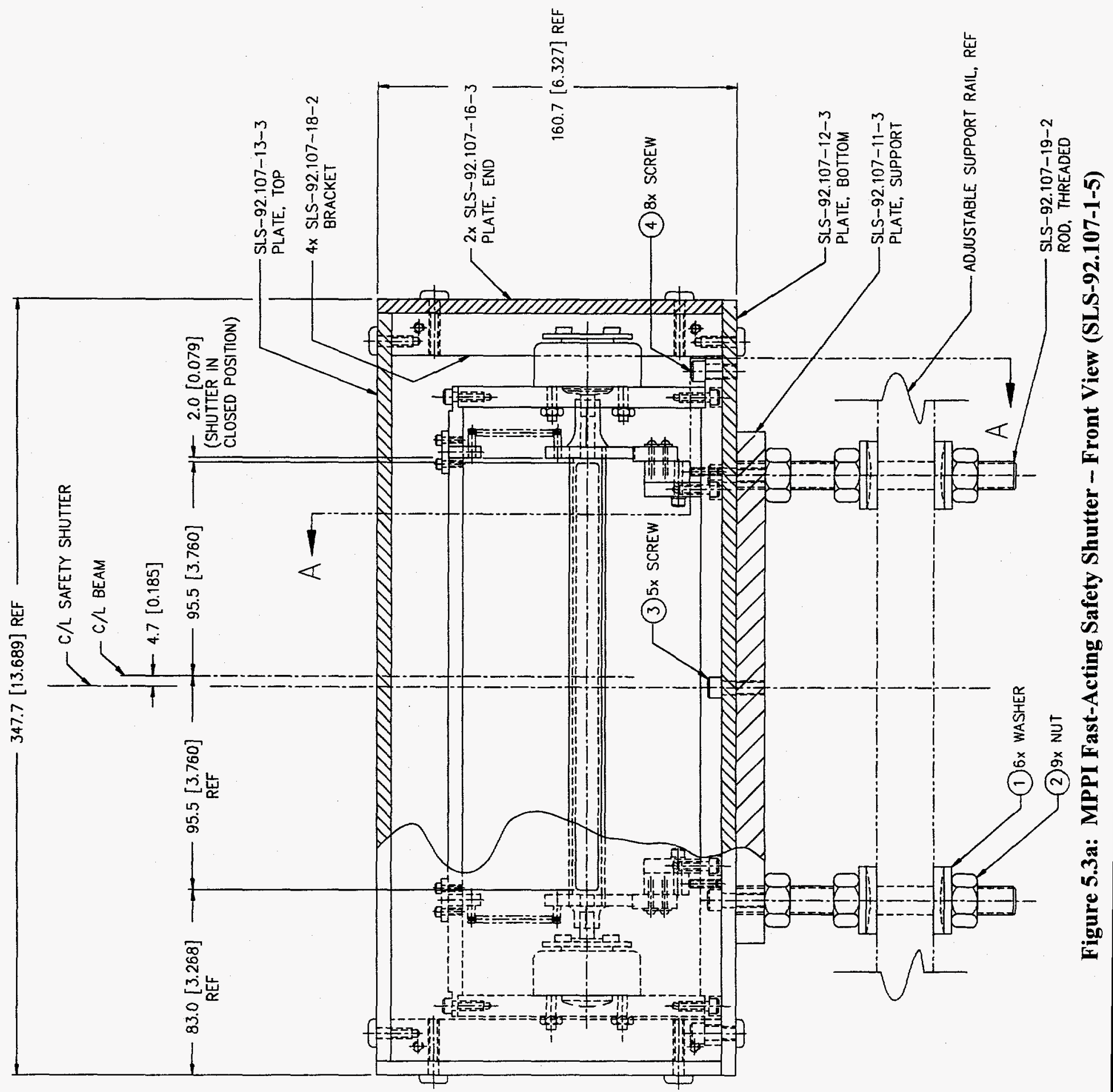




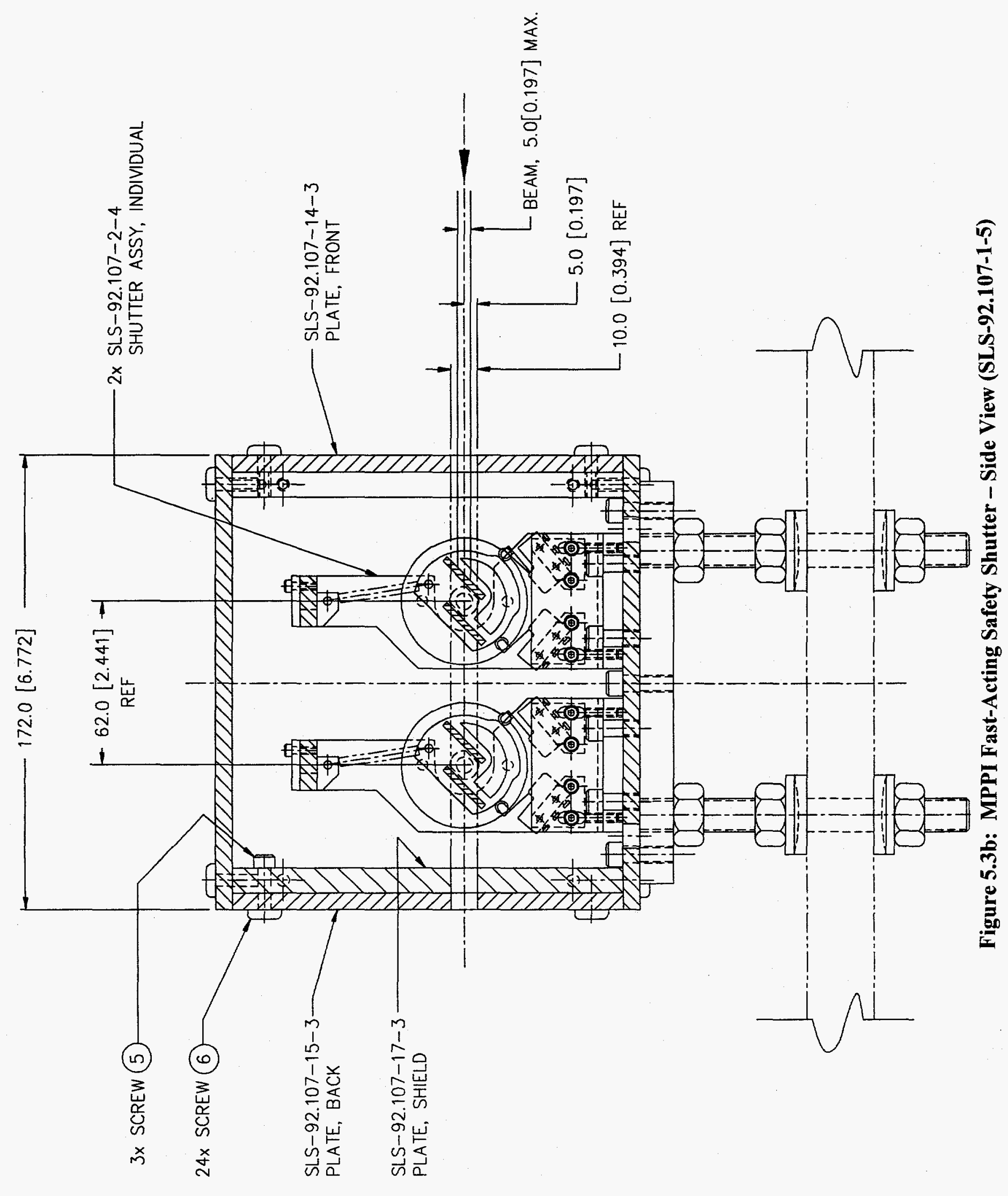




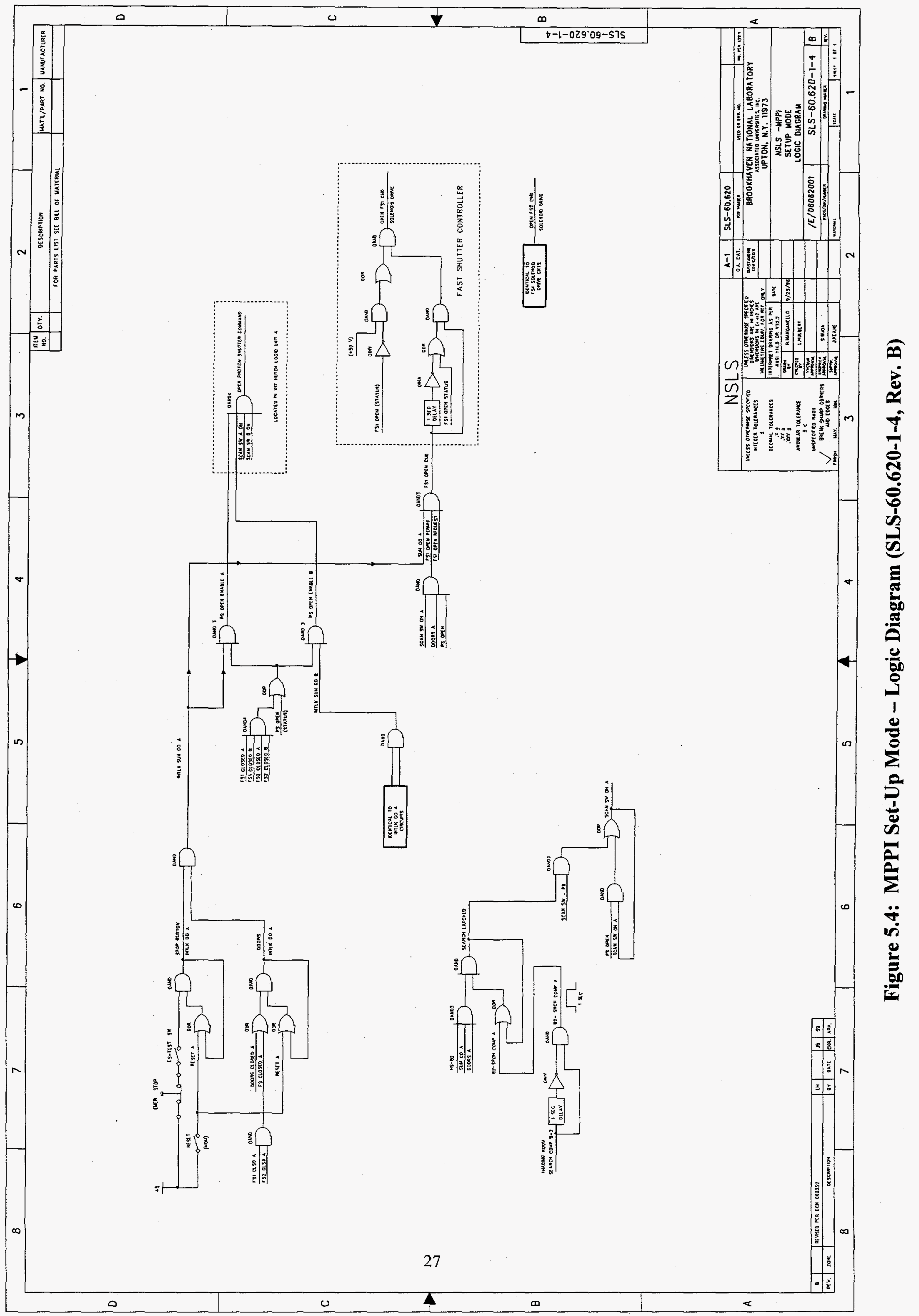




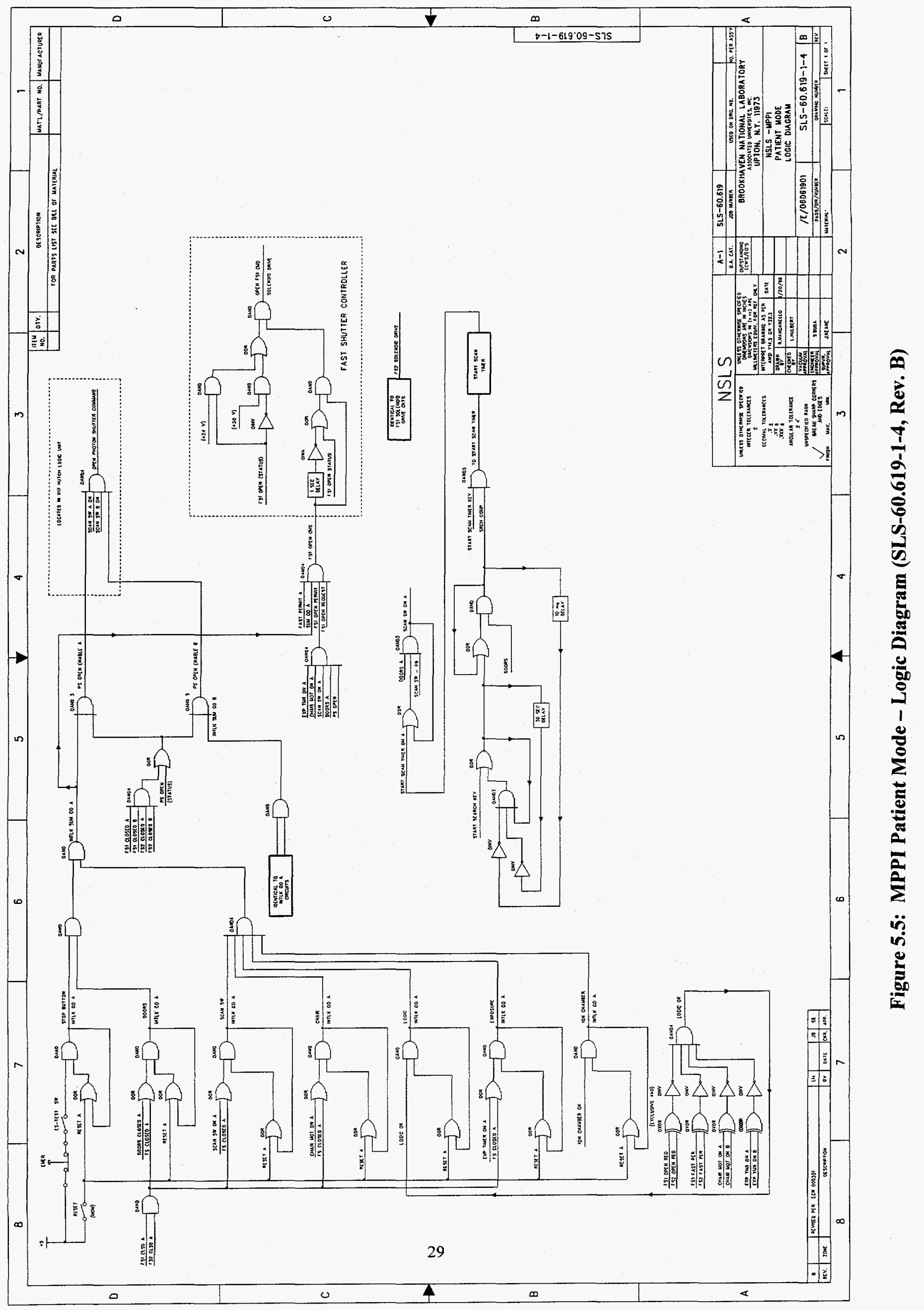




\subsection{APPENDIX}

6.1 MPPI Setup Mode and Patient Mode Test Procedures

6.2 MPPI X17 Beamline Connection Diagram (SLS 61.75-1-X-X)

6.3 Hutch Logic X17B2A (SLS 61.143-1-X-X)

6.4 MPPI System Interlocks A (SLS 61.155-1-X-X)

6.5 MPPI System Interlocks B (SLS 61.156-1-X-X)

6.6 MPPI System Search (SLS 61.157-1-X-X)

6.7 MPPI System Shutter Status (SLS 61.158-1-X-X)

6.8 MPPI System Shutter Control (SLS 61.159-1-X-X)

6.9 MPPI System Scan Switch Control (SLS 61.160-1-X-X)

6.10 MPPI System Logic Interlock (SLS 61.161-1-X-X)

6.11 MPPI System Chair Motion A (SLS 61.162-1-X-X)

6.12 MPPI System Exposure Timer A (SLS 61.163-1-X-X)

6.13 MPPI System DC Power (SLS 61.164-1-X-X)

6.14 MPPI System Extender Card (SLS 61.165-1-X-X)

6.15 MPPI System CAMAC Buffer (SLS 61.166-1-X-X)

6.16 MPPI System Crate Interlock (SLS 61.167-1-X-X)

6.17 MPPI System Chair Motion B (SLS 61.168-1-X-X)

6.18 MPPI System Exposure Timer B (SLS 61.169-1-X-X)

6.19 MPPI System Fast Shutter Controller (SLS 61.170-1-X-X)

6.20 MPPI System Chair Encoder Driver (SLS 61.171-1-X-X)

6.21 X17 Beamline Disconnect Aux. Box (SLS 61.175-1-X-X)

6.22 Beamline Disconnect X17/18 Logic Box (SLS 61.189-1-X-X)

6.23 MPPI System Physician's Panel (SLS 61.190-1-X-X)

6.24 MPPI System Status Panel Clk/Intlk Fault/Go Ind. (SLS 61.191-1-X-X)

Note: Diagrams 6.2 through 6.24 are not included in this document due to the lack of space. Copies of these diagrams may be obtained from the NSLS Design Group. 
MPPI Setup Mode Test rev. $12 / 17 / 96$ Page 1 of 8

GENERIC SET-UP MODE

MPPI TEST PROCEDURE

Date

Test personnel

Start time Finish time

1. Before starting this test, the source of $\overline{\text { radiation must be locked }}$ out.

X-RAY RING LOCKED OUT AND TAGGED
OR
X-17 BEAMLINE LOCKED OUT AND TAGGED

OR

X-17BI BACKSTOP IS IN PLACE, LOCKED, AND RED TAGGED

In the following tests, shutter status lights on APPI panels are used to indicate shutter position. Step 14. verifies that these indicators are accurate.

PREPARATION :

A. Use key to switch to SETUP MODE

B. Reset if any faults are latched.

C. Do a lamp test on all three panels

2. Kirk lock Reception Room and Fluoroscopy Room doors. Search room, turning physicians key in check station adjacent to the Reception Room door. Close the physicians door and Kirk lock. Press the external check station push button. Transfer kirk keys, insert and turn key in the SRU.

Turn START SCAN keyswitch on the operators panel.

SEARCH TIMER light on APPI panel does not light

Open door to break search.

3. Close all (3) doors, but do not search hutch. Send a SHUTTER OPEN REQUEST using computer program IGOR.

Fast shutters do not open 1

Shutter OPEN REQUEST lights on APPI panel come on 1

4. Leave SHUTTER OPEN REQUEST signal active. Push SCAN SWITCH.

Fast shutters do not open 1

NOTE: Through step $11 .$, be prepared for multiple observations during a limited time.

SEnd SHUTTER CLOSE REQUEST. (IGOR)

5. Kirk lock Reception Room and Fluoroscopy Room doors. Search imaging room. Put kirk keys in transfer unit and put transfer key into SRU, but do not activate. (Do not rotate final key) Push SCAN SWITCH while sonolert is sounding.

Photon Shutter does not open

Scan switch does not latch

$S / R$ timer does not go on 
MPPI Setup Mode Test rev. $12 / 17 / 96$ page 2 of 8

6. After sonolert stops push SCAN SWITCH again.

Scan switch does not latch

Photon shutter does not open

7. Search imaging room, complete kirk key sequence, turning transfer key in SRU. Press SCAN SWITCH while sonolert is sounding.

Scan switch does not latch

Activate SHUTTER OPEN REQUEST.

Deactivate SHUTTER OPEN REQUEST.

Fast Shutters do not open 1 _

8. After sonolert stops, push SCAN SWITCH until Photon shutter is open, then release.

Scan switch does latch

Photon shutter opens

Fast. Shutters do not open 1 2

SRU light goes out

9. Activate SHUTTER OPEN REQUEST.

Fast shutters open $1+2$

10. Deactivate SHUTTER OPEN REQUEST.

Fhoton shutter remains open

Fast shutters close 1

2

11. Remove the cover on the fast shutter enclosure in the

Monochrometer Room. Observe the shutter indicators at the physician's panel.

The FAST ACTING SHUTTER CLOSED light is on

Manually rotate Fast shutter 1 until the FAST ACTING SHUTTERS CLOSED

light goes out.

Observe that in this position Fast

shutter 1 would still block the xray beam

Release Fast Shutter 1 .

Manually rotate Fast shutter 2 until the FAST ACTING SHUTTERS CLOSED

light goes out.

Observe that in this position Fast

shutter 2 would still block the xray beam

Release Fast Shutter 2 .

Manually rotate Fast shutter 1 until it is fully open. The FAST ACTING SHUTTER CLOSED light goes out

The FAST ACTING SHUTTER OPEN 1 ight does not go on

While holding shutter 1 , rotate Fast Shutter 2 Eully open.

The FAST ACTING SHUTTER OPEN light goes on 
MPPI Setup Mode Test rev. 12/17/96 Page 3 of 8

Release Fast Shutters 1 and 2 .

Both shutters close firmly against their stops 1

2

The FAST ACTING SHUTTER CLOSED light is on

Replace the cover on the Fast shutter enclosure

INTERLOCK FAULT CHECKS

STOP BUTTONS

Open the Imaging room Note: RESET after each fault.

12. Press each STOP button in turn.

stop button fault (1)

Summary fault $A$

B

stop button fault (2)

Summary fault A

B

Physician's panel stop button fault (3)

Summary fault A

B

13. Reset EMERGENCY STOP fault at B2 logic unit but do not reset fault at APPI panel. Do complete search with Kirk Key sequence. Scan switch does not operate

14. Reset faults. Do complete search as above, push sTop button. stop button fault light goes on

15. Activate SHUTTER OPEN REQUEST.

Fast Shutters do not open 1

Deactivate SHUTTER OPEN request.

16. Reset faults. Do complete search with Kirk Key sequence.

Press SCAN SWITCH until Photon Shutter opens, then release:

Activate SHUTTER OPEN REQUEST

SCAN SWITCH does operate and latch

Press STOP button on operators panel.

Fast shutters do open 1 2

Fast Shutters close I 2

Photon shutter clases

Stop button fault light goes on

Reset faults. Deactivate SHUTTER OPEN request. 
MPPI Setup Mode Test rev. $12 / 17 / 96$ Page 4 of 8

17. Throw STOP BUTTON A test switch to test position.

Photon shutter enable light goes out

STOP BUTTON FAULT goes on

SUMMARY FAULT A goes on

SUMMARY GO B remains lit

Return test switch $A$ to the active position. Reset fault.

18. Throw STOP BUTTON B test switch to test position.

Photon shutter enable light goes out

STOP BUTTON FAULT goes on

SUMMARY FAULT B goes on

SUMMARY GO A remains lit

Return test switch B to the active position. Reset fault.

DOORS

19. Place switch holders on appropriate door switches ( 4 for each door section). Place latch devices on door locks so keys can be removed. complete key sequence and turn key in SRU. The imaging room search must be done after each switch test in order to reset the scan Timer and get the Photon shutter oper, so after each switch test, release the switch holder on a HUTCH LOGIC door switch 1 to dump the search.

Repeat the following sequence for each MPPI door switch test:

Search hutch. Push SCAN switch. Activate SHUTTER OPEN REQUEST.

Remove switch holder from MPPI door switch. Observe indicator lights and check off. Deactivate SHUTTER OFEN REQUEST. Remove switch holder from HUTCH LOGIC doorswitch 1 to dump search. Replace all holders to prepare for next switch test.

MPPI Door Switch 1

$\begin{array}{cccc}\text { PHYS } & \text { RECEP } & \text { RECEP } & \text { FLOUR } \\ \text { MAIN } & \text { AUX } & \text { MAIN } & \text { AUX }\end{array}$

Fast shutter 1 closes

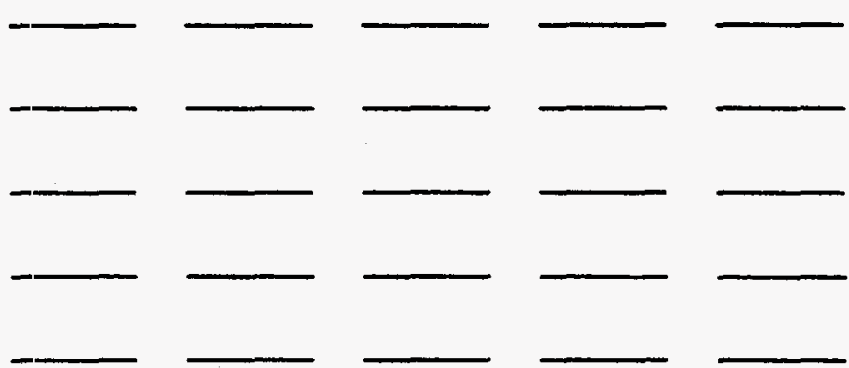

Photon Shutter closes

Scan Switch A deactivates

Door fault lights

Summary Fault A lights 
MPPI Setup Mode Test rev. 12/17/96 Page 5 of 8

Repeat for Door switch 2 .

MPPI Door Switch 2

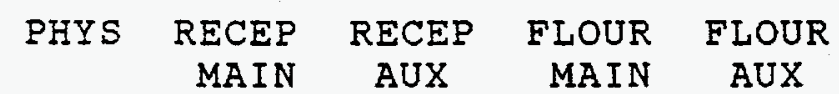

Fast Shutter 1 closes

Fast shutter 2 closes

Photon Shutter closes

Scan Switch B deactivates

Door fault lights

Summary Fault B lights

20. Remove all doorswitch holders. Check operation of all four switches on each door. Open each door slowly and listen for a distinct click for each switch.

MPPI doorswitch 1

MPPI doorswitch 2

Hutch logic doorswitch 1

Hutch logic doorswitch 2

\section{AUXILIARY TEST SWITCHES}

21. Throw the FSI OPEN REQUEST test switch to the BYPASS position. Do the entire system operation sequence, including pressing the SCAN SWITCH. ACtivate a SHUTTER OPEN REQUEST via the computer.

Fast Shutter 1 does not open

Deactivate the SHUTTER OPEN REQUEST.

Fast shutter 2 does open

Return the FSI OPEN REQUEST test switch to the normal active position. Throw the FS2 OPEN REQUEST switch to the BYPASS position. Activate a SHUTTER OPEN REQUEST via the computer.

Fast shutter 1 does open

Deactivate the SHUTTER OPEN REQUEST.

Fast shutter 2 does not open

Return all switches to the normal active position. 
MPPI Setup Mode Test rev. 12/17/96 Page 6 of 8

22. Throw the SCAN SWITCH A test sivitch to the BYPASS position. Close the Photon Shutter. Press the Scan Switch. Activate a SHUTTER OPEN REQUEST via the computer.

Scan switch A does not operate

Scan switch B does operate

rast shutter 1 does not open

Deactivate the SHUTTER OPEN REQUEST.

Fast shutter 2 opens

Return the SCAN SWITCH A test switch to the normal active position.

Press the CLOSE PHOTON SHUTTER button.

Throw the SCAN SWITCH B test switch to the test position. Press and HOLD DOWN the Scan Switch. Activate al SHUTTER OPEN REQUEST via the computer.

Scan switch $A$ does operate

Scan switch B does not operate

Fast shutter 1 opens

Deactivate the SHUTTER OPEN REQUEST.

Fast Shutter 2 does not open

Return the SCAN SWITCH B test switch to the normal active position.

23. Return all test switches to the active mode: On the RELAY PANEL:

OPEN PERMIT FSI__ FS2
SCAN SWITCH A_
STOP BUTTON A_ B

OPEN REQUEST FSI FS2

On the DIGITAL PANEL:

LOGIC INTLK BYPASS

\begin{tabular}{lll} 
CLOCK ENABLE & $\mathrm{A} 1 \_$ & $\mathrm{A} 2$ \\
CLOCK ENABLE & $\mathrm{B} 1 \_\mathrm{B} 2$ \\
\hline
\end{tabular}


MPPI Setup Mode Test rev. 12/17/96 Page 7 of 8

TEST OF REACHBACK FEATURE (Set-up Mode)

CAUTION !!

During this portion of the test it is necessary to enable beamline $\mathrm{X}-17 \mathrm{~B}$.

NO SWITCH HOLDERS OR OTHER BYPASSES MAY BE USED DURING

THIS PART OF THE TEST, SINCE IT WOULD BE POSSIBLE TO BRING

BEAM INTO THE AREA. It is possible to do the test without opening the $x-17 B$ safety shutter. However, if the shutter is opened, beam will come into the angiography area, and the $x$-ray ring will trip when the test is conducted.

24. If $X-17 B I$ cannot be made safe for beam (missing shielding etc) then the test may be conducted only if the $x$-ray ring has been tagged off as when regular beamline interlock tests are done.

$$
\begin{array}{r}
x \text {-ray ring interlock is tagged off } \\
\text { oR } \\
x-17 B \text { is safe for beam }
\end{array}
$$

25. Verify that all door switch holders have been removed and switches tested for proper function. (step 21 above)

verify that all test switches are returned to the active mode. (step 44 above)

26. Search and secure the Transport hutch. Make sure that the backstop in the BI hutch is in the out-of-beam position. Search and secure the BI hutch. Put X-17B1-B2 "on line" (lockout key in place and CRSC keys enabled). Open monochromator hutch. Send an observer with a radio to the front end disconnect panel at the sawtooth. Verify that the "beamline secure" indicator lights for $\mathrm{X}-17 \mathrm{BI}$ are out.

27. Close the air supply valve for the photon shutter. Search the mono hutch. Verify that the beamline secure lights come on (one light comes on when the door is closed and the KIRK key is secured, the other comes on when the warning is complete).

28. Search the Imaging Room, and complete the Kirk Key transfer. Press and release the SCAN SWITCH.

$$
\text { Photon Shutter does open }
$$

29. Press the Photon Shutter CLOSE button on the logic box, while announcing this on the radio.

At the Front End:

The top "beamline secure" light goes out within two seconds of pressing the CLOSE button

At the Logic Unit:

Photon shutter "closed" indicator light does not come on

PHOTON SHUTTER FAIL light on logic unit comes on 
MPPI Setup Mode Test rev. $12 / 17 / 96$ Page 8 of 8

30. Open the Monochromator room and turn on the air supply. Photon shutter does close

Reset the PHOTON SHUTTER FAIL on the XI7B2 logic unit. PHOTON SHUTTER FAIL does not reset w/o SOR key

31. Search the Monochromator room. Exercise the PHOTON SHUTTER by pressing and releasing the SCAN SWITCH.

Photon Shutter does open

Press the shutter CLOSE button on the logic box.

Photon Shutter does close

PHOTON SHUTTER FAIL light does not come on

Beamline secure light does not trip

This completes the test of the Interlock Reach Back feature in set-up Mode. 
MPPI ANGIO Patient Mode Test rev. 12/17/96 Page 1 of 16

\section{ANGIOGRAPHY PATIENT MODE}

MPPI TEST PROCEDURE

Date

Test personnel

start time Finish time

1. Before starting this test, the source of radiation must be locked out.

$\begin{array}{ccc}\text { X-RAY } & \text { RING LOCKED OUT AND TAGGED } \\ \text { OR } & \\ \text { X-17 B } & \text { BEAMLINE LOCKED OUT AND TAGGED } \\ \text { OR }\end{array}$

$X-17 B I$ BACKSTOP IS CLOSED, LOCKED AND RED TAGGED

In the following tests, shutter status lights on APPI panels are used to indicate shutter position. step 12 . verifies that these indicators are accurate.

PREPARATION :

A. Use key to switch to PATIENT MODE.

B. Reset if any faults are latched.

C. Do a lamp test on all three panels

Note: Photon and fast shutter open/closed lamps do not test.

2. Kirk lock Reception Room and Fluoroscopy Room doors. Search hutch, pressing check station buttons and closing physicians door. Complete the search and Kirk Key sequence as for SET-UP mode. After the sonolert stops sounding, observe the SCAN TIMER light.

SCAN TIMER light on MPPI panel does not light

Send a SHUTTER OPEN REQUEST using the computer program, IGOR. SHUTTER OPEN REQUEST lights on MPPI panel come on 1

Fast shutters do not open 1

Leave the SHUTTER OPEN REQUEST active. Push the SCAN SWITCH.

SCAN SWITCH does not latch

Photon Shutter does not open

Fast Shutters do not open 1 _ 2

Deactivate the SHUTTER OPEN REQUEST. (IGOR)

3. Remove Kirk Keys and unlock all three doors. Close but do not lock the Reception and Fluoroscopy Room doors. Exit the Angiography Room by the Physician's door, and close but do not lock. Turn the START SCAN keyswitch on the operators panel.

SCAN TIMER light does NOT come on 
MPPI ANGIO Patient Mode Test rev. 12/17/96 Page 2 of 16

Press the SCAN SWITCH.

SCAN SWITCH ACTIVE does NOT come on A__ B

Photon Shutter does NOT open

Send a SHUTTER OPEN REQUEST. Fast Shutters do not open 1 _-

Deactivate the SHUTTER OPEN REQUUST.

4. Enter the Angiography Room and turn the key in the

Physicians check station adjacent to the Reception Room door.

Leave the room, and immediately turn the key in the operators

panel. (Within $15 \mathrm{sec}$ ). Do not close the door.

Press the SCAN SWITCH.

SCAN TIMER light does not come on

SCAN SWITCH ACTIVE does NOT come on A_B

4a. Enter the Angiography Room and turn the key in the Physicians check station. Start timing with a stop watch. After 30 seconds, close the door.

Turn the key in the operators panel.

READY light does not come on

Press the SCAN SWITCH.

SCAN TIMER light does not come on

SCAN SWITCH ACTIVE does NOT come on $A$

5. Enter the Angiography Room and turn the key in the Physicians check station adjacent to the Reception Room door. Leave the room and close the door. Turn the key in the operators panel.

SCAN TIMER light does come on

Press and hold the SCAN SWITCH during the SCAN TIMER ON CYCle.

SCAN SWITCH ACTIVE does come on $A$

Photon Shutter does open

Send a SHUTTER OPEN REQUEST.

Fast Shutters do not open 1

Release the SCAN SWITCH.

PHOTON SHUTTER closes

Again press the SCAN SWITCH.

SCAN SWITCH ACTIVE does not come on A

B

PHOTON SHUTTER does not open

Fast shutters do not open 1

Deactivate SHUTTER OPEN REQUEST.

NOTE: SET CHAIR MOTION to 10 cycles via the computer, using program CHT2. Chair speed is preset in software to $12 \mathrm{~cm} / \mathrm{sec}$.

6. Do NOT activate the START SCAN keyswitch. Start a chair cycle (via computer program CHT2) so that the motion light comes on and off, and SHUTTER OPEN REQUESTS are issued. Observe during 
MPPI ANGIO Patient Mode Test rev. 12/17/96 Page 3 of 16

the MOTION ON part of the cycle, when the SHUTTER OPEN REQUEST is also on:

Fast shutters do not open 1

Press and hold the SCAN SWITCH through one complete cycle of the chair.

SHUTTER OPEN REQUEST goes on and off $1 \_2$

Photon shutter does not open

Release the SCAN SWITCH.

Fast shutters do not open 1

7. Start the SCAN TIMER from the operators panel. Start the chair motion for 10 cycles. Press the SCAN SWITCH, while the chair motion is on.

SHUTTER OPEN REQUEST goes on and off

Photon Shutter does open

Fast shutters do open 1 - 2

Release the SCAN SWITCH when the Fast shutters are closed.

8. Run the chair motion without SHUTTER OPEN REQUESTS. (Use program CHTI). Start the SCAN TIMER from the physician's panel. Push and hold the SCAN SWITCH DURING the SCAN TIMER CYCle.

NO SHUTTER OPEN REQUESTS OCCUT $1 \_2$

Photon shutter does open

Exposure timer does not go on

Fast shutters do not open 1

Release the SCAN SWITCH.

9. Stop the chair motion for this step. Start the SCAN TIMER

from the physician's panel. Push and hold the sCAN SWITCH during the SCAN TIMER cycle.

Activate the SHUTTER OPEN REQUEST. (IGOR program)

Photon Shutter does open

Exposure timer does go on

SHUTTER OPEN REQUEST does come on

Fast Shutters do not open 1

2

Release the SCAN SWITCH.

Photon shutter closes

Deactivate the SHUTTER OPEN REQUEST.

10. Set up chair motion with SHUTTER OPEN REQUESTS. (CHT2). DO a complete search. Start the SCAN TIMER with the physician's key. Push and hold the SCAN SWITCH. During the part of the cycle when the fast shutters are closed, open the physician's door, then 
MPPI ANGIO Patient Mode Test rev. $12 / 17 / 96$ Page 4 of 16

close it again. Hold the SCAN SWITCH until the chair cycle is completed.

Photon shutter closes

Fast shutters don't respond to subsequent open requests 1 2

Scan Switch ENABLE light goes out A__ B

Scan Switch ACTIVE light goes out $A$

Release the SCAN SWITCH.

10a. Set up chair motion with SHUTTER OPEN REQUESTS. (CHT2). Do a complete search. Start the SCAN TIMER with the physician's key. Push and hold the SCAN SWITCH. During the part of the cycle when the fast shutters are open, open the physician's door, then close it again. Hold the SCAN SWITCH until the chair cycle is completed.

Photon Shutter closes

Fast shutters don't respond to subsequent open requests 1

Scan Switch ENABLE light goes out $A_{-}$

Scan Switch ACTIVE light goes out $A_{-}$

ThE INTERLOCK GO light goes out

The INTERLOCK FAULT light is on

Reset the INTERLOCK FAULT.

11. Do a complete search. Start the chair motion. (cHr2) start the SCAN TIMER from the operators panel. Push and hold the SCAN SWITCH DURING the SCAN TIMER Eycle. Observe the EXPOSURE TIMER when the first SHUTTER OPEN REQUEST occurs:

Exposure timer does go on

Fast Shutters open 1 2

Release the SCAN SWITCH while the shutters are in the CLOSED part of the cycle.

Photon Shutter closes

Fast shutters stay closed on the next cycle 1 _ 2 Once again push the SCAN SWITCH. Photon Shutter does not open Fast Shutters do not open 1 - 2

Release the SCAN SWITCH.

12. Remove the top cover on the fast shutter enclosure in the Monochrometer Room. Observe the shutter indicators at the physician's panel.

The FAST ACTING SHUTTER CLOSED light is on 
MPPI ANGIO Patient Mode Test rev. 12/17/96 Page 5 of 16

Manually rotate Fast shutter 1 until the FAST ACTING SHUTTERS CLOSED light goes out. Observe that in this position Fast

Release Fast shutter 1 .

shutter 1 would still block the xray beam

Manually rotate Fast shutter 2 until the FAST ACTING SHUTTERS CLOSED light goes out.

observe that in this position Fast

Release Fast shutter 2 .

shutter 2 would still block the xray beam

Manually rotate Fast shutter 1 until it is fully open.

The FAST ACTING SHUTTER CLOSED light goes out

The FAST ACTING SHUTTER OPEN light does not go on

While holding shutter 1 , rotate Fast shutter 2 fully open. The FAST ACTING SHUTTER OPEN light goes on

Release Fast shutters 1 and 2 .

Both shutters close firmly against their stops 1_ 2

The FAST ACTING SHUTTER CLOSED light is on

Replace the cover on the Fast shutter enclosure

\section{INTERLOCK FAULT CHECKS}

STOP BUTTONS

Open the ANGIOGRAPHY ROOM.

Note: RESET after each fault at the MPPI panel and at the HUTCH LOGIC PANEL, unless noted differently.

13. Press each STOP button in turn.

stop button fault (1)

Summary fault A

B

Hutch Logic Emerg. Stop fault

stop button fault (2)

Summary fault A

B

Hutch Logic Emerg. Stop fault

Operators panel stop button fault (3)

Do not reset this fault.

Summary fault A 
MPPI ANGIO Patient Mode Test $r e v .12 / 17 / 96$ Page 6 of 16

14. Do NOT reset the fault at the MPPI panel. Do a complete search. Turn the SCAN START keyswitch, then press the SCAN SWITCH.

Photon shutter does not open

15. Reset faults. Start the SCAN timer. Push STOP button after SCAN timer starts.

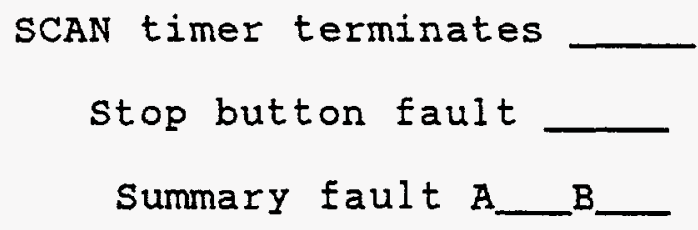

Do NOT reset these faults.

16. Activate SHUTTER OPEN REQUEST. (IGOR)

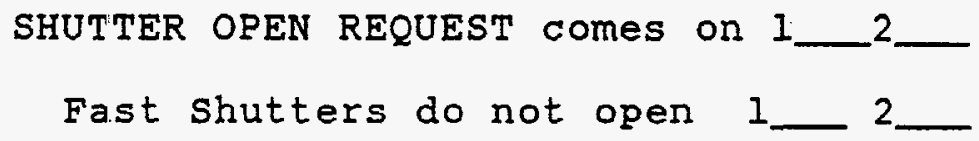

Deactivate SHUTTER OPEN request.

Reset faults.

17 Do complete operational sequence with the chair in motion, and the SHUTTER OPEN REQUEST active. Observe during the OPEN REQUEST part of the cycle:

Fast Shutters do open 1 2

Press STOP button on physician's panel:

Fast Shutters close 1 2

Photon shutter closes stop button fault Summary fault $A$

Reset faults. Deactivate chair motion and SHUTTER OPEN request. 18. Throw EMERGENCY STOP BUTTON A test switch to test position. Photon shutter enable light goes out STOP BUTTON INTERLOCK GO goes out STOP BUTTON FAULT goes on SUMMARY FAULT A goes on 
MPPI ANGIO Patient Mode Test rev. 12/17/96 Page 7 of 16

\section{SUMMARY GO B remains green}

Return test switch A to the active position. Reset fault.

19. Throw STOP BUTTON B test switch to test position.

Photon shutter enable light goes out

STOP BUTTON INTERLOCK GO goes out

STOP BUTTON FAULT goes on

SUMMARY FAULT B goes on

SUMMARY GO A remains green

Return test switch B to the active position. Reset fault.

\section{INTERLOCK FAULT CHECKS}

DOORS

20. Place switch holders on appropriate door switches ( 2 for each door section). Do complete operational sequence with the chair in motion, (CHT2) and the SHUTTER OPEN REQUEST active. During a part of the cycle when the Fast shutters are OPEN, remove switch holder from MPPI switch 1. Observe indicator lights and check off. Replace all holders and RESET FAULTS to prepare for next switch test. Repeat this sequence for each No. 1 switch.

\section{MPPI Door Switch 1}

Fast Shutters $1 \& 2$ close

Photon shutter closes

Door fault lights

Summary Fault A lights

Scan Switch Fault lights

Search Complete drops out

\section{PHYS RECEP RECEP FLOUR FLOUR MAIN AUX MAIN AUX}

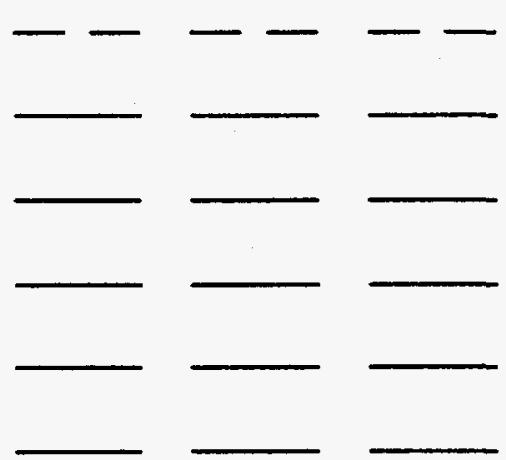


MPPI ANGIO Patient Mode Test rev. 12/17/96 Page 8 of 16

21. Repeat 20. for Door switch 2 .

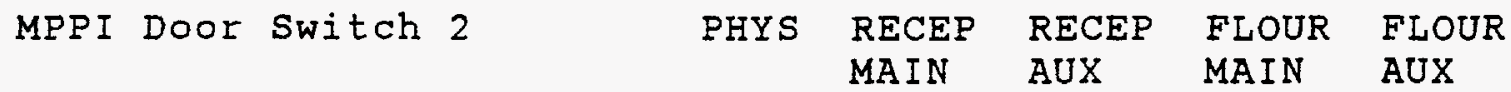

Fast Shutters $1 \& 2$ close

Photon shutter closes

Door fault lights

Summary Fault B lights

Scan Switch Fault lights

Remove all doorswitch holders. Check operation of all four switches on each door. Open each door slowly and listen for a distinct click for each switch.

MPPI doorswitch 1

MPPI doorswitch 2

Hutch logic doorswitch 1

Hutch logic doorswitch 2

\section{INTERLOCK FAULT CHECKS}

\section{SEQUENCE FAULTS}

22. Reset faults, and close all doors. Do a complete search. start the SCAN timer from the physician's panel. Push and hold the SCAN SWITCH DURING the SCAN timer cycle. start the CHAIR MOTION/SHUTTER OPEN REQUEST cycle (computer program CHT2). Release the SCAN SWITCH when the shutters are open.

Fast shutters close $1{ }_{2}^{2}$

Summary fault $\mathrm{A}$

Reset faults.

Scan switch fault

23. The chair motion speed is preset in the computer for 12 $\mathrm{cm} / \mathrm{s}$. Set the chair motion thumbwheels on the digital panel for 10. Do a complete search. Start the SCAN timer from the operators panel. Push and hold the SCAN SWITCH during the SCAN timer cycle. Start the chair motion/SHUTTER OPEN REQUEST cycle. When the shutters are open, quickly turn thumbwheel $A$ to 12 .

Fast shutters close 1 Chair motion fault 
MPPI ANGIO Patient Mode Test rev. $12 / 17 / 96$ Page 9 of 16

\author{
Summary fault $A$ \\ Logic fault
} B

Fast Permit FSI light goes out

Chair Intlk fault $A$

Fast Shutters remain closed on subsequent cycles 1 __ 2 Reset faults and reset thumbwheel A to 10 .

24. Repeat 23., but with thumbwheel switch B.

Fast Shutters close 1__ 2

Chair motion fault

Summary fault $A$

Logic fault

Fast Permit FS2 light goes out

Chair Intlk fault $B$

Fast shutters remain closed on subsequent cycles I

Reset faults and reset thumbwheel B to 10 .

NOTE: In steps 25 and 26 , if the Exposure Timer times out when the shutters are not open, no Exposure Timer fault will occur. The thumbwheel must be changed slightly and the test repeated.

25. Set Exposure timer A to 13 seconds and Exposure timer B to 23 seconds. Repeat scan cycle as above except hold the SCAN SWITCH until the exposure timer times out.

Fast Shutters close 1

EXPOSURE TIMER ON A goes out

EXPOSURE TIMER ON B stays on several seconds longer

Exposure Timer fault

Summary fault A

B

Logic fault

26. Repeat 25., but with Exposure timer $A$ at 23 seconds and Exposure timer $B$ at 13 seconds.

Fast Shutters close 1

EXPOSURE TIMER ON B gOES out

EXPOSURE TIMER ON A stays on several seconds longer 
MPPI ANGIO Patient Mode Test rev. 12/17/96 Page 10 of 16

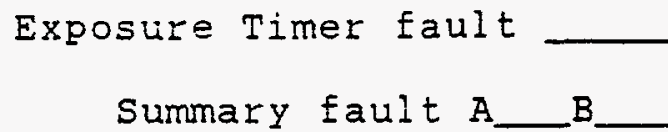

Logic fault

27. With the Exposure Timer thumbwheels set to the same time (e.g. 14 seconds) run through the system sequence, but hold the scan switch on until the Exposure Timer times out. If it times out when the Fast shutters are CLOSED, change the timers and repeat the entire sequence until the Exposure Timer times out when the Fast shutters are OPEN. Time with a stop watch.

Exposure Timer times out when the Fast shutters are open

Photon shutter closes

Fast Shutters close 1

1

Exposure Timer fault

Summary fault B

Time in secorids equals thumbwheel setting

28. Set Exposure Timer thumbwheels to the same time, but one or two seconds different from step 27, so time out occurs when the Fast shutters are NOT open. Change and repeat sequence until this is achieved. Hold Scan Switch on until the Exposure Timer times out. Time with a stop watch.

Fhoton Shutter does not close

Fast shutters do not open on subsequent cycles 1

Time in seconds equals thumbwheel setting

AUXILIARY TEST SWITCHES

29. Throw the Logic Interlock Bypass switch to BYPASS. Throw the FS1 OPEN REQUEST test switch to the BYPASS position. Do the entire system operation sequence (CHT2) including pressing the SCAN SWITCH.

The Photon Shutter OPEN indicator

lights but the Photon shutter does not open

Fast Shutter 1 does not open

Fast shutter 2 does open

Return the FSI OPEN REQUEST test switch to the normal active position. 
MPPI ANGIO Patient Mode Test rev. 12/17/96 Page 11 of 16

30. Repeat 29., except use the FS2 OPEN REQUEST switch.

The Photon Shutter OPEN indicator

lights but the Photon shutter does not open

Fast shutter 1 does open

Fast shutter 2 does not open

Return all switches to the normal active position.

31. Throw the Logic Interlock Bypass switch to the Active position. Set the FSI OPEN REQUEST switch to BYPASS. Send a SHUTTER OPEN REQUEST. (IGOR)

FS1 OPEN REQUEST does not light

FS2 OPEN REQUEST does light

Logic fault

Deactivate request, reset faults.

summary fault A B

32. Repeat 31 , but with FS2 OPEN REQUEST test switch.

FSI OPEN REQUEST does light

FS2 OPEN REQUEST does not light

Logic fault

Return all test switches to the active position.

Summary fault A B

33. Throw the SCAN SWITCH A test switch to the BYPASS position. Do the entire system operation sequence, including pressing the SCAN SWITCH.

Photon Shutter does not operate

Scan switch A does not operate

Scan switch B does operate

Return the SCAN SWITCH A test switch to the active position.

34. Repeat 33., except throw the SCAN SWITCH B test switch to the BYPASS position.

Photon Shutter does not operate

Scan switch A does operate

Scan switch 8 does not operate

Return the SCAN SWITCH B test switch to the active position. 
MPPI ANGIO Patient Mode Test rev. 12/17/96 Page 12 of 16

35. Throw the CLOCK FAULT Al test switch to the BYPASS position. Fast Permit FSI light goes out

Logic Intlk fault

Summary Fault

B

Clock Fault A

Return the CLOCK FAULT AI switch to the active position. Reset faults. Repeat for CLOCK FAULI A2 switch.

Clock Fault A

36. Throw the Logic Interlock Bypass switch to the test position. Do an operational sequence. One person observes the Fs lights, while the other throws the CLOCK FAULT Al switch to the BYPASS position WHILE THE SHUTTERS ARE OPEN.

FAST PERMIT I light goes out

FSI closes immediately

FS2 continues to cycle

Clock Eault A

Return the CLOCK FAULT AI switch to the active position. Reset faults. Repeat for CLOCK FAULr A2 switch.

Clock Fault A

Reset faults. Return the Logio Interlock Bypass to the active position. Return the CLOCK FAULT A switch to the active position.

37. Repeat 35., except with the CLOCK FAULT B1 and B2 test switches.

Fast Permit FS2 light goes out

Logic Intlk fault

Summary Fault $\mathrm{A}$

Clock Fault BI

Clock Fault B2

38. Repeat 36., but with CLOCK FAULT BI and B2 switches.

FAST PERMIT 2 light goes out

FS2 closes immediately

FSl continues to cycle 
MPPI ANGIO Patient Mode Test rev. $12 / 17 / 96$ Page 13 of 16

\section{Clock Fault BI \\ Clock Fault B2}

Reset fauls, return all switches to active positions.

39. Place the LOGIC INTERLOCK BYPASS switch in the BYPASS

position. Throw the FAST PERMIT FSI test switch to the BYPASS

position. Set the pulse width thumbwheels on the digital panel

for 10. Do a complete operational sequence. When the shutters are open, quickly turn thumbwheel A to 12:

Fast Shutters close 1
Chair motion fault
Summary fault A

Logic fault does not light

Fast Permit FSI light stays on

Chair Interlock fault A

Return the FAST PERMIT FSI switch to the active position. Reset faults and reset thumbwheel A to 10 .

40. Throw the FAST PERMIT FS2 test switch to the BYPASS position. Repeat step 39. When the shutters are open, quickly turn thumbwheel $B$ to 12:

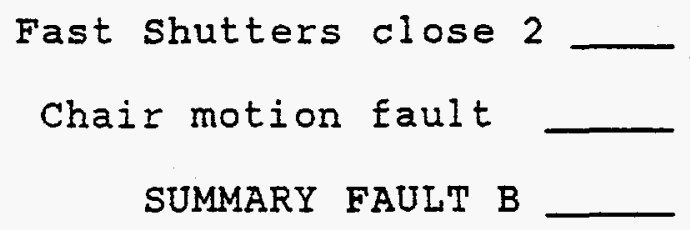

Logic fault does not light

Fast Permit FS2 light stays on

Chair Interlock fault B

Return the FAST PERMIT FS2 switch to the active position. Reset faults and reset thumbwheel $B$ to 10 .

41. Leave the LOGIC INTERLOCK BYPASS switch in the BYPASS position. Set Exposure timer $A$ to $I l$ seconds and Exposure timer $B$ to 21 seconds. Repeat the complete scan cycle, except hold the SCAN SWITCH until the exposure timer times out.

Exposure Timer fault

SUMMARY FAULT A

Reset faults.

SUMMARY GO B remains green 
MPPI ANGIO Patient Mode Test rev. 12/17/96 Page 14 of 16

42. Leave the Logic Interlock Eypass switch in the test position. Set Exposure timer A to 21 seconds and Exposure timer $B$ to 11 seconds. Repeat scan cycle as above except hold the SCAN SWITCH until the exposure timer times out.

Exposure Timer fault

SUMMARY FAULT B

SUMMARY GO A remains green

Return the LOGIC INTERLOCK BYPASS switch to the active position. Reset faults.

43. Set the thumbwheel switches to the nominal positions:

$$
\begin{array}{r}
\text { Exposure Timer A-25 B }-25 \\
\text { Chair Motion A }-10 \\
B-10
\end{array}
$$

44. Return all test switches to the active mode:

On the RELAY PANEL:

EMERG STOP BUTTON A

EMERG STOP BUTTON B

LOGIC INTERLOCK BYPASS

FSI OPEN REQUEST

FS2 OPEN REQUEST

FSI OPEN PERMIT

FS2 OPEN PERMIT

SCAN SWITCH A

SCAN SWITCH B

On the DIGITAL PANEL:

CLOCK FAULT AI A2

CLOCK FAULT BI B2 
MPPI ANGIO Patient Mode Test rev. 12/17/96 Page 15 of 16

\author{
TEST OF REACHBACK FEATURE (Patient Mode) \\ CAUTION ! !
}

During this portion of the test it is necessary to enable beamline $\mathrm{X}-17 \mathrm{~B}$. NO SWITCH HOLDERS OR OTHER BYPASSES MAY BE USED DURING THIS PART OF THE TEST, SINCE IT WOULD BE POSSIBLE TO BRING BEAM INTO THE AREA. It is possible to do the test without opening the $X-17 B$ safety shutter. However, if the shutter is opened, beam will come into the angiography area, and the $x-r a y$ ring will trip when the test is conducted.

45. If $X-17 B I$ cannot be made safe for beam (missing shielding etc) then the test may be conducted only if the $x$-ray ring has been tagged off as when regular beamline interlock tests are done.

$$
\begin{array}{r}
X \text {-ray ring interlock is tagged off } \\
\text { OR } \\
X-17 B \text { is safe for beam }
\end{array}
$$

46. Verify that all door switch holders have been removed and switches tested for proper function. (step 21 above)

Verify that all test switches are returned to the active mode. (step 44 above)

47. Search and secure the Transport hutch. Make sure that the backstop in the $B I$ hutch is in the out-of-beam position. Search and secure the B1 hutch. Put $X-17 B 1-B 2$ "on line" (lockout key in place and CRSC keys enabled). Open monochromator hutch. Send an observer with a radio to the front end disconnect panel at the sawtooth. Verify that the "beamline secure" indicator lights for $\mathrm{X}-17 \mathrm{BI}$ are out.

48. Close the air suppiy vaive for the photon shutter. Search the mono hutch. The beamline secure lights come on (one light comes on when the door is closed, the other comes on when the warning is complete).

49. Search the Angiography Room, using the physician's key and closing the doors. Do not lock the doors or do the Kirk Key transfer. Complete the search with the physician's key at the operator's panel. Press and hold the SCAN SWITCH.

Photon Shutter does open 
MPPI ANGIO Patient Mode Test rev. $12 / 17 / 96$ Page 16 of 16

50. Release the SCAN SWITCH, while announcing this on the radio. At the Front End:

The top "beamline secure" light goes out within two seconds of releasing the switch

At the Logic Unit: Photon shutter "closed" indicator light does not come on

PHOTON SHUTTER FAIL I ight comes on on logic unit

51. Open the Monochromator room and turn on the air supply. Photon shutter does close

Reset the PHOTON SHUTTER FAIL on the X17B2 logic unit.

PHOTON SHUTTER FAIL does not reset w/o SOR key

52. Search the Monochromator room and Angiography room. Exercise the PHOTON SHUTTER by pressing and releasing the SCAN SWITCH.

Photon shutter does open

Photon Shutter does close

PHOTON SHUTTER FAIL light does not come on

Beamline secure light does not trip

This completes the test of the Interiock Reach Back feature in Patient Mode. 